\title{
Projection Subtypes of Rat Neostriatal Matrix Cells Revealed by Intracellular Injection of Biocytin
}

\author{
Yasuo Kawaguchi, ${ }^{1}$ Charles J. Wilson, ${ }^{2}$ and Piers C. Emson ${ }^{3}$ \\ 'Laboratory for Neural Systems, Frontier Research Program, RIKEN, Wako, 351-01 Japan, 2Department of Anatomy and \\ Neurobiology, University of Tennessee, Memphis, Tennessee 38163, and ${ }^{3}$ Department of Neuroendocrinology, Institute of \\ Animal Physiology and Genetics Research, Babraham, Cambridge, CB2 4AT, United Kingdom
}

Individual neostriatal-matrix spiny neurons were stained intracellularly with biocytin after intracellular recording in vivo, and their axons were traced into the globus pallidus (GP), entopeduncular nucleus (EP), and/or substantia nigra (SN). The locations of the neurons within the matrix compartment of the neostriatum (NS) were established by immunocytochemical counterstaining of sections containing the cell bodies using antibodies for calbindin-D28K. This allowed nearly complete visualization of the axonal projections of single NS neurons.

On the basis of their intrastriatal axonal arborizations, matrix spiny neurons could be divided into 2 types. One type, which was the more common, had local axonal arborizations restricted to the region of the dendritic field, often with axon collaterals arborizing within the dendritic field of the cells of origin. A second, less common, cell type in the matrix had local axon collaterals distributed widely in the NS. Among matrix neurons with restricted local collateral fields, 3 subtypes could be distinguished on the basis of their efferent axonal projections. Type I cells projected only to the GP. Type lla cells projected to the GP, EP, and SN pars reticulata. Type Ilb cells projected to the GP and SN but not to the EP. The shapes and densities of the GP arborizations varied in the 3 cell types, with the cells projecting only to the GP (type I) projecting more heavily and filling a larger volume there than type II cells. The dendrites and intrastriatal axon collaterals of 3 subtypes were similar in morphology. The class of matrix spiny neurons with intrastriatal axon collaterals distributed widely in the NS were observed to project to the GP. Projections beyond the GP were not identified for this cell type, but could not be ruled out. Somatodendritic morphologies of neurons did not differ according to the projection site.

These results demonstrate that NS matrix spiny cells are more heterogeneous in their efferent projection patterns than previously suspected on the basis of retrograde axonal trac-

\footnotetext{
Received Apr. 25, 1990; revised June 18, 1990; accepted June 22, 1990.

This work was supported by Frontier Research Program, Japan (Y.K.) and by NIH Grants NS20743 and RCDA NS01078 (C.J.W.). We wish to thank Ms Brenda Ross for her excellent technical assistance. We also thank Prof. Edward G. Jones (RIKEN, University of California at Irvine) and Dr. Zao Cheng Xu and Dr. Ronald Cowan (University of Tennessee at Memphis) for helpful suggestions and encouragement.

Correspondence should be addressed to Charles J. Wilson, Department of Anatomy and Neurobiology, University of Tennessee at Memphis, 875 Monroe Avenue, Memphis, TN 38163.
}

Copyright (c) 1990 Society for Neuroscience $0270-6474 / 90 / 103421-18 \$ 03.00 / 0$ ing and immunocytochemical studies. As predicted by those previous studies, there is a class of matrix neurons that projects only to the GP. Presumably, these cells contain enkephalin. Cells projecting to the $S N$ and EP, and so presumably containing substance $P$, give off a small projection to the GP, as well, and differ in their collateralization patterns within the 3 major target nuclei.

Among the first classification schemes for neurons of the CNS was the one introduced by Golgi, which distinguished neurons on the basis of their axonal arborizations. Of course, Golgi's dichotomy between projection cells and interneurons is still fundamental, but most subsequent investigators have followed the example of Cajal in constructing cell classes along various dimensions of somatic and dendritic morphology.

On these grounds, neostriatal (NS) spiny projection neurons have long been considered to be a single cell class, because of their homogeneous somatodendritic morphology. More recently, however, the application of a combination of immunocytochemical staining techniques and retrograde axonal tracing has revealed inhomogeneity among the spiny neurons in their content of a variety of neuropeptides, including enkephalin, substance $P$, and dynorphin (Kanazawa et al., 1977; Vincent et al., 1982; Chesselet and Graybiel, 1983; Beckstead and Kersey, 1985; Penny et al., 1986; Gerfen and Young, 1988). These differences between spiny neurons have been shown to be related to axonal projections of the cells, with cells projecting primarily to 1 set of targets, in the entopeduncular nucleus (EP) [internal segment of globus pallidus (GP)] and the substantia nigra (SN) being more immunoreactive for substance $\mathrm{P}$ and dynorphin, while those that are most heavily stained for enkephalin project primarily to the GP (external segment). Therefore, a more useful categorization scheme for NS spiny neurons may be one that relies on the differences in axonal, rather than somatodendritic, morphology.

An additional dimension to the problem is presented by the existence of a mosaic structure within the NS, composed of 2 interdigitating tissue compartments differing in cytochemical makeup, afferent and efferent targets, and developmental history (e.g., Graybiel et al., 1979; Gerfen, 1984, 1985; Jimenez-Castellanos and Graybiel, 1989). For example, spiny neurons in the larger of these compartments, called the matrix, are rich in calbindin (e.g., Gerfen et al., 1985; Kawaguchi et al., 1989a), undergo final cell division and migration later in development (e.g., Brand and Rakic, 1984; Graybiel and Hickey, 1982), and preferentially receive inputs from sensory and motor cortices 
(e.g., Gerfen, 1984; Donoghue and Herkenham, 1986). The same cell type located in the smaller compartment, called striosomes or patches, contains much less calbindin, has a precocious development, and receives most of its input from a more restricted region of the cerebral cortex. Equally important, striosomal and matrix spiny-projection neurons differ in their efferent projections, with the cells of the striosomes projecting preferentially to the SN pars compacta, while nigral projections of the matrix neurons go primarily to the pars reticulata (Graybiel et al., 1979; Gerfen, 1984, 1985; Jimenez-Castellanos and Graybiel, 1989).

Population labeling techniques such as retrograde axonal tracing and immunocytochemistry cannot be expected to provide the definitive description of cell classes based on the axonal arborizations of individual neurons. Examination of the axonal arborizations of single cells is possible using intracellular staining techniques. In fact, the first indication that there may be different classes of NS projection neurons based on axon targets was reported by Chang et al. (1981), based on examination of the axons of single spiny NS neurons stained by intracellular injection of HRP. Intracellular injection of NS spiny neurons with HRP in vivo has enabled a partial analysis of the local and efferent axonal arborizations of those cells (Kitai et al., 1976; Preston et al., 1980; Wilson and Groves, 1980; Bishop et al., 1982). But in the study of the efferent projections of these neurons, Chang et al. (1981) could trace HRP-filled axons no farther than the caudal boundary of the GP. The short range of axonal staining possible after intrasomatic injection of HRP also required use of a restricted subpopulation of NS neurons located close to the boundary of the GP.

The development of a more sensitive intracellular staining method based on biocytin (Horikawa and Armstrong, 1988) offers a possible solution to the problems of long-range staining of individual axons. This method has been shown superior to HRP in staining dendritic and axonal fields in several in vitro preparations, including NS tissue slices (Horikawa and Armstrong, 1988; Kawaguchi et al., 1989a). In the experiments reported here, intracellular staining with biocytin was used to examine the dendritic fields, local axonal arborizations, and long-range projections of NS spiny neurons. Because of their prevalence, and to avoid additional complications introduced by differential projections of neurons in the patch (or striosome) and matrix compartments of the NS (e.g., Graybiel et al., 1979; Gerfen, 1984, 1985), the study was restricted to spiny neurons of the matrix compartment, identified by counterstaining of sections by immunocytochemistry for the $28-\mathrm{kDa}$ calciumbinding protein calbindin, which is rich in matrix, but not patch spiny neurons (Gerfen et al., 1985; Kawaguchi et al., 1989a). The biocytin method has allowed an almost complete visualization of the axonal projections of single NS neurons and has revealed a variety of different cell subpopulations distinguished by their axonal projection patterns.

A preliminary report of some of the findings has been made (Kawaguchi et al., 1989b).

\section{Materials and Methods}

Animal preparation. Intracellular recording and injection of biocytin were performed on 27 Sprague-Dawley rats weighing from 240 to 390 $\mathrm{gm}$. Initially, the rats were anesthetized with urethane $(1.2-1.4 \mathrm{gm} / \mathrm{kg}$, i.p.). Supplementary doses of ketamine $(10 \mathrm{mg} / \mathrm{kg}, \mathrm{i} . \mathrm{m}$.) were administered every $1-2 \mathrm{hr}$. Dexamethasone $(0.3 \mathrm{mg} / \mathrm{kg})$ was given to reduce brain edema. The skull was exposed, and holes were drilled for placement of stimulating and recording electrodes. Cisternal drainage and suspension of the rat by the tail were performed to reduce brain pulsations. Rectal temperature was maintained at $38^{\circ} \mathrm{C}$ by a heating pad.

Intracellular recording and staining. Stimulating electrodes were pairs of stainless-steel insect pins $(00)$ separated by $0.5 \mathrm{~mm}$. They were oriented mediolaterally and inserted into the pyramidal tract [anteriorposterior (AP), 0.5; lateral (Lat), 0.5-1.0; dorsoventral (DV), 0.4] and thalamus (AP, 5.5; Lat, 0.5-1.0; DV, 3.9). Recording micropipettes were broken under microscopic control and filled with 2-3\% biocytin (Sigma) dissolved in $1.0 \mathrm{M}$ potassium acetate $(50-80 \mathrm{M} \Omega)$. After placement of the microelectrode in the neostriatum, the exposed surface of the brain was covered with soft paraffin wax to reduce brain pulsation. Recordings were made using a conventional active-bridge amplifier. Neurons were initially identified by their firing patterns and responses to stimulation and showed the typical characteristics of neostriatal spiny cells as reported previously (Wilson et al., 1983a,b). Following intracellular recordings, neostriatal neurons were labeled with biocytin by passage of depolarizing current pulses (1.0-2.0 nA, 200-msec duration) at $2.5 \mathrm{~Hz}$ for 10-30 $\mathrm{min}$. One or 2 injections were performed in each animal. Survival periods following intracellular labeling ranged from 2 to $6 \mathrm{hr}$.

Histology. At the end of the experiment, a lethal dose of urethane was administered, and animals were perfused intracardially with isotonicbuffered saline followed by $4 \%$ paraformaldehyde in $0.1 \mathrm{M}$ phosphate buffer $(\mathrm{pH}, 7.4)$. After perfusion, the brain was removed from the skull and postfixed overnight at $4^{\circ} \mathrm{C}$ with the fixative containing $2 \%$ paraformaldehyde in phosphate buffer. Fifty- $\mu \mathrm{m}$ sections were cut in the sagittal plane using a Vibratome. After several washes with phosphatebuffered saline (PBS), the sections were incubated in a $0.5 \%$ solution of Triton X-100 in PBS containing avidin-biotin-HRP complex (ABC solution, Vector Labs) at a dilution of 1:200 for $4 \mathrm{hr}$ at room temperature. Sections were rinsed and reacted with diaminobenzidine tetrahydrochloride (DAB, $0.05 \%$ ) and $\mathrm{H}_{2} \mathrm{O}_{2}(0.003 \%)$ in PBS. All sections except those containing somata of injected cells were postfixed in $0.1 \%$ osmium tetroxide in $0.1 \mathrm{M}$ phosphate buffer for $10 \mathrm{~min}$ and mounted on slides.

To reveal the tissue compartment containing each injected cell, a section containing the soma already stained for biocytin was counterstained by immunohistochemistry for the $28 \mathrm{-kDa}$ calcium-binding protein calbindin. A rabbit antiserum was raised against calbindin by one of us (P. C. Emson). Sections containing somata of injected cells were incubated for $4 \mathrm{hr}$ in 2\% normal goat serum in PBS followed by incubation for $16 \mathrm{hr}$ in antiserum diluted 1:5000 in PBS containing 2\% normal goat serum and $0.25 \%$ Triton $\mathrm{X}-100$. They were then washed thoroughly and incubated in biotinylated goat anti-rabbit serum (1:200 in PBS) for $1 \mathrm{hr}$. The distribution of bound antiserum was revealed by incubation in $\mathrm{ABC}$ solution followed by treatment with $\mathrm{DAB}$ and $\mathrm{H}_{2} \mathrm{O}_{2}$ in the same concentrations used for biocytin staining. After several washes, these sections were mounted on glass slides. Patches were calbindin poor, and the matrix had dense labeling of calbindin-positive somata and puncta.

The somata, dendrites, and axons of the intracellularly labeled neurons were drawn from individual sections at $600 \times$ using a $60 \times, 1.4$ numerical aperture objective and a camera lucida.

\section{Results}

\section{Compartmental identification of biocytin-injected cells}

Spiny ncurons injected intraccllularly with biocytin were often very darkly stained, allowing unambiguous identification of all dendritic and axonal processes in the vicinity of the neurons. This was especially valuable in sections counterstained for calbindin, as it provided the strong contrast required to distinguish the intracellularly stained cell processes from the more lightly stained processes of calbindin-positive cells. An example showing the appearance of an intracellularly stained matrix cell in a section counterstained with calbindin immunocytochemistry is shown in Figure 1, $A$ and $B$. The matrix compartment is rich with calbindin-positive neurons and perforated with smaller islands of calbindin-poor NS tissue. These have previously been shown to correspond to the regions of $\mu$-opiate-receptor-rich NS neuropil and to the regions of low AChE activity and low somatostatin immunoreactivity (e.g., Gerfen et al., 1985). For purposes of consistency with the literature on the rat NS, they 

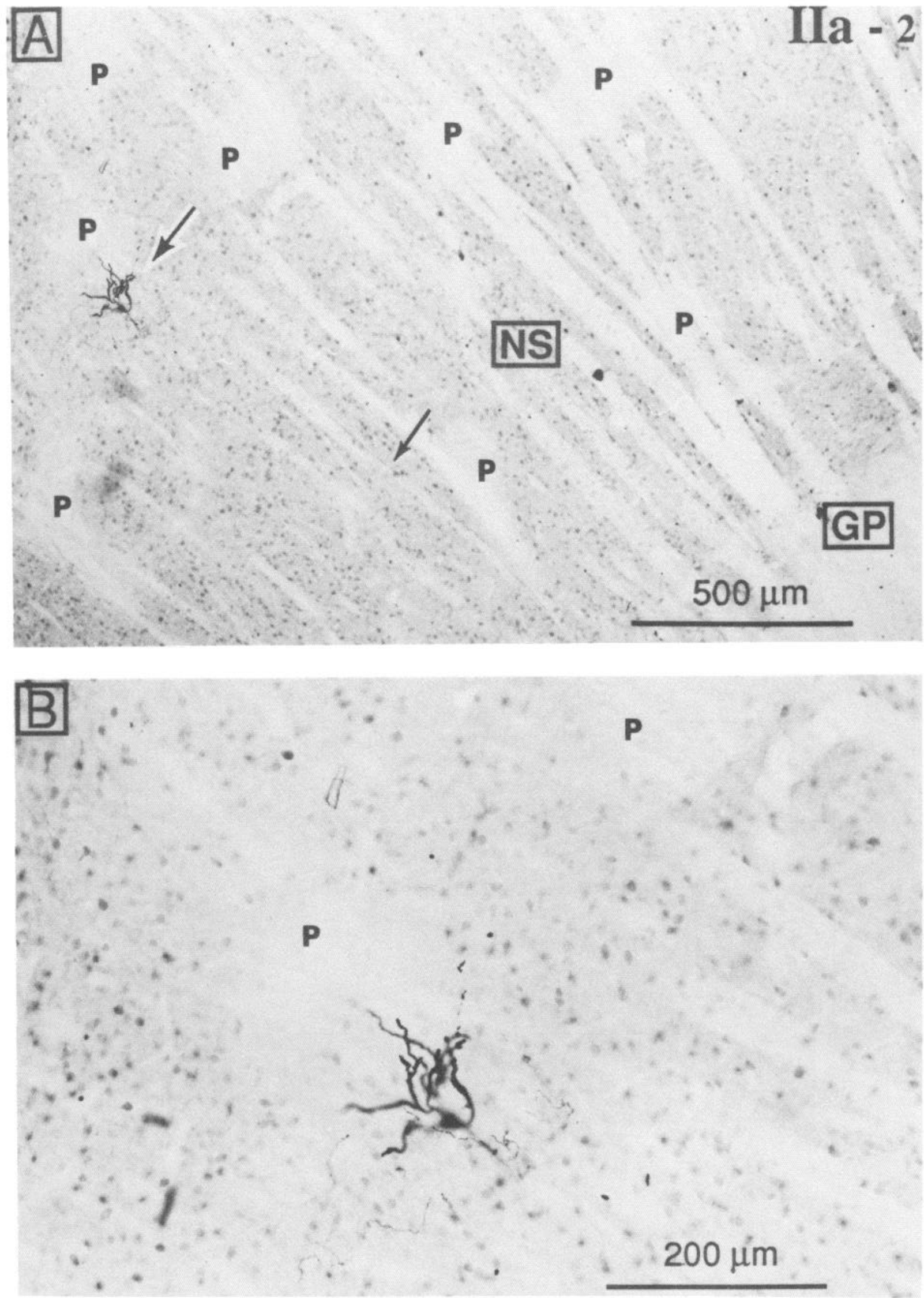

Figure 1. Compartmental identification of biocytin-injected neostriatal cells in matrix by calbindin immunohistochemistry. This cell (IIa-2) belonged to the calbindin-rich matrix compartment. $A$, The biocytin-stained cell (larger-arrow) is visible in the matrix, near the boundary with a calbindin-poor patch $(P)$. A portion of the main efferent axon of this cell is also visible within an internal capsule fascicle (smaller arrow). $B$, A higher magnification view of the injected cell shown in $A$ : spiny dendrites and local collaterals restricted within the matrix area. The plane of the section is parasagittal, with rostral to the left and dorsal to the top. 


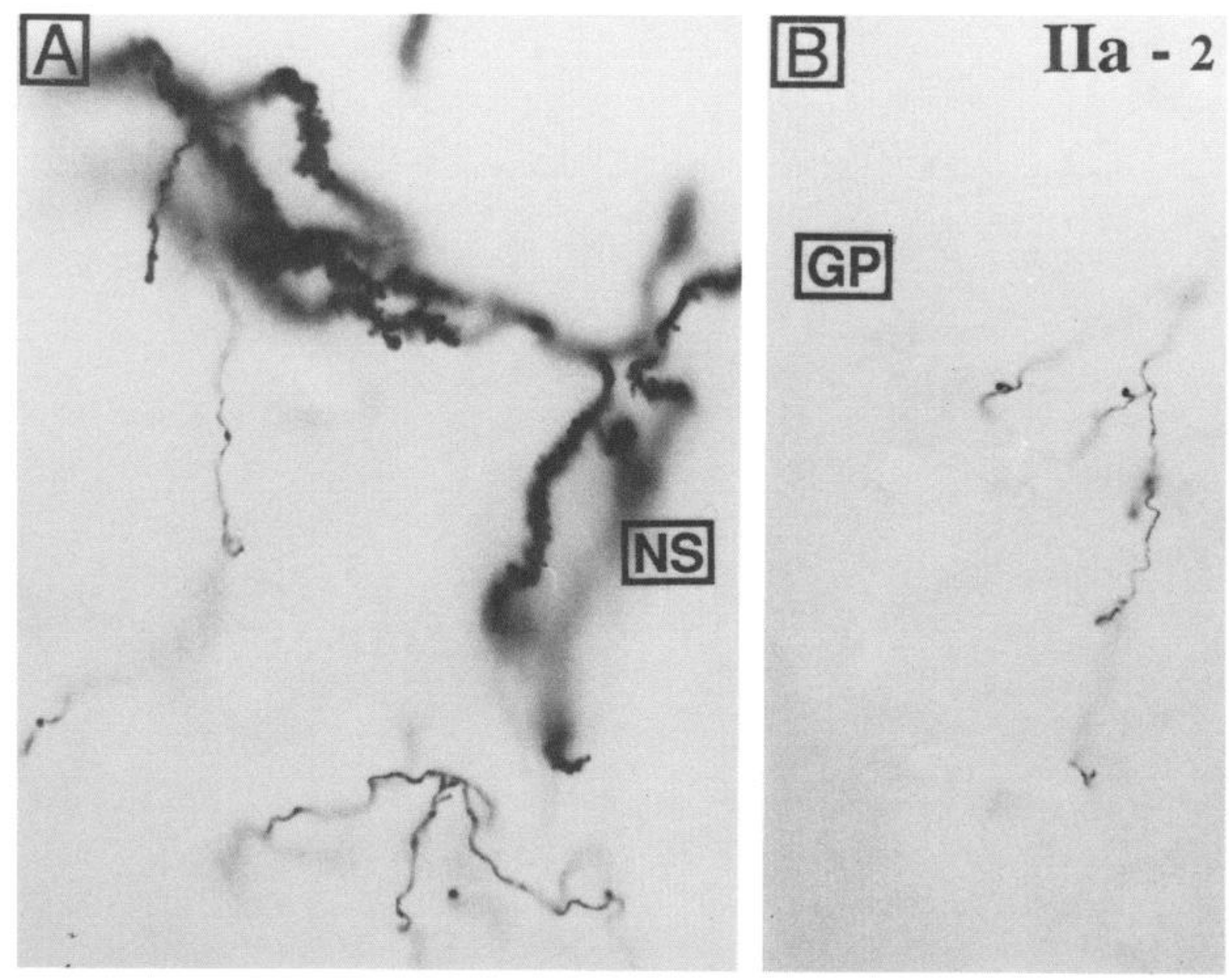

C

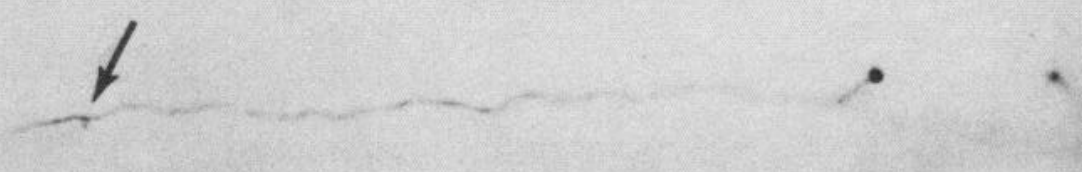

ED D

$20 \mu \mathrm{m}$

SN 
will be referred to as patches, but this is meant to be synonymous with striosomes.

In Figure $1, A$ and $B$, an intracellularly stained neuron is seen in the matrix close to the boundary with a calbindin-poor patch. A portion of the dendritic field and the local axonal arborization are seen in this single $50-\mu \mathrm{m}$ section (Fig. $1 B$ ). All the matrix cells included in the sample exhibited the morphological features of the densely spinous projection neurons that have been reported previously in intracellular-staining studies (e.g., Preston et al., 1980; Chang et al., 1981). Their somata were 10-20 $\mu \mathrm{m}$ in diameter and emitted several smooth dendritic trunks that usually branched within $20 \mu \mathrm{m}$ of their origins to give rise to densely spiny branches. The spiny dendrites formed a radiating dendritic field that extended 100-250 $\mu \mathrm{m}$ from the soma. Dendrites and local axonal branches were both restricted to the calbindin-rich matrix compartment containing the cell body, as previously reported from intracellular labeling experiments (Penny et al., 1988; Kawaguchi et al., 1989a). This distorted the dendritic fields of neurons located near the boundary between the patch and matrix regions. In addition, however, dendritic fields of these cells appeared to be distorted in ways unrelated to the boundaries between patches and the matrix as visualized using immunocytochemistry for calbindin. An example of this kind of distortion can be seen in the dendritic field of the cell in Figure $1 B$. Local axonal branches and the initial part of the trajectory of the efferent axon were very densely stained and could be easily identified despite the calbindin counterstaining. A portion of the projecting axon of the neuron is visible in an internal capsule fascicle in Figure $1 A$. Tracing the axons over long distances was impeded by the immunocytochemical stain, so all sections except those containing the cell bodies were intensified by treatment with osmium tetroxide and were examined with no further counterstaining.

The appearance of the stained cell processes in these sections is illustrated in Figure 2, $A-D$. The intensity of staining of dendrites was sometimes so great after osmium intensification as to obscure some details of their morphology. This can be seen in the densely stained dendrites in Figure $2 A$. The axonal branches within the NS (Fig. 2A) and elsewhere along their paths (Fig. $2 B-D$ ) were much more easily visualized after this treatment. In the past, the uncertainty associated with any failure to identify axonal branches has been a serious problem with intracellular staining of axons with HRP. If one could not see a branch arising from a faint and faded axon as it coursed through a nucleus, it often could not properly be concluded that no branch was present. There might have been one that was too faint to identify. The solution to this problem is more intense axonal staining. The density of staining achieved in the GP and the EP after intracellular staining in the NS, illustrated in Figure 2, $B$ and $C$, was strong enough to be certain that all axonal branches were visible. Axonal varicosities and terminal axonal side branches were readily identified (Fig. $2 C$ ). This could not be said of staining in $\mathrm{SN}$, as seen in Figure $2 D$. It was possible to identify those axons that entered the $\mathrm{SN}$, but the details of their arborizations

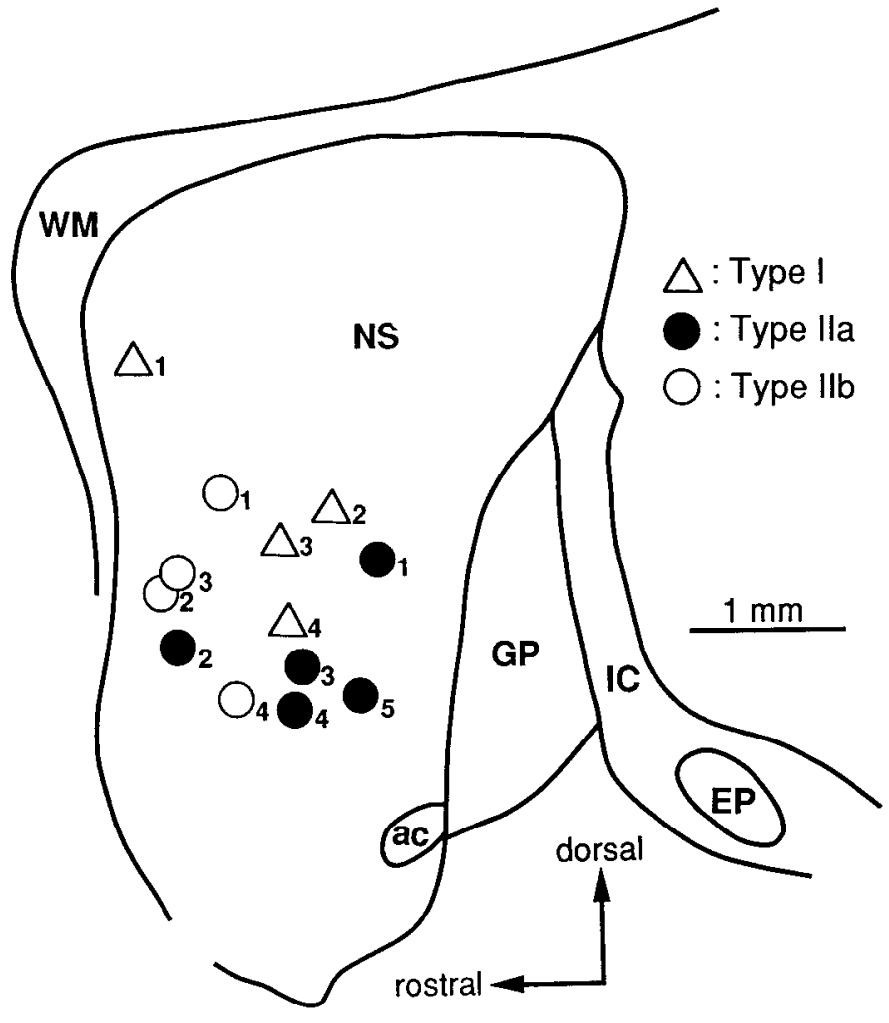

Figure 3. Distribution of biocytin-labeled type I (triangles), type IIa (solid circles), and type IIb (open circles) matrix cells with local axon collaterals arborizing near the domain of the parent dendrites. These cells were sampled in the middle part of the NS dorsoventrally to optimize calbindin immunocytochemical identification of compartmental boundaries. ac, anterior commissure; IC, internal capsule; WM, white matter.

could not be discerned because of the lighter staining of axons so far from the point of intracellular injection.

Matrix spiny cells could be divided into 2 groups using the distributions of their intrastriatal axon collaterals. One group of matrix cells had local axon collaterals that remained restricted to the area near the parent dendritic domain, whereas the other group of cells had axon collaterals over a much wider portion of the NS. These categories corresponded to 2 types of spinyprojection neurons described in previous studies (Bishop et al., 1982; Kawaguchi et al., 1989a). Most stained cells were of the former type, and those could be further classified into 3 subtypes by patterns of efferent projection.

\section{Projection subtypes of matrix spiny cells with the local axon collateral arborizations close to the parent dendritic domain}

The sample described here consists of 13 spiny neurons that satisfied the following 3 morphological criteria: (1) their axons were stained enough to identify their arborizations in the GP, $\mathrm{SN}$, or EP; (2) their local axonal collateral arborization was

Figure 2. Dendrites and axons of neostriatal spiny cells filled with biocytin. These are from the same cell as in Figure 1 (IIa-2), but from sections treated in osmium tetroxide rather than counterstained for calbindin immunoreactivity. $A$, Spiny dendrites and local axon collaterals within the neostriatum. $B$, Collateral branches and boutons within the GP. $C$, The main axon and collaterals with boutons in the EP. The branch point of the collateral seen in the lower part of the micrograph is indicated at the arrow. $D$, Efferent axons in the rostral pole of the SN pars reticulata. Axons going to the SN usually became faint just before entering it. 


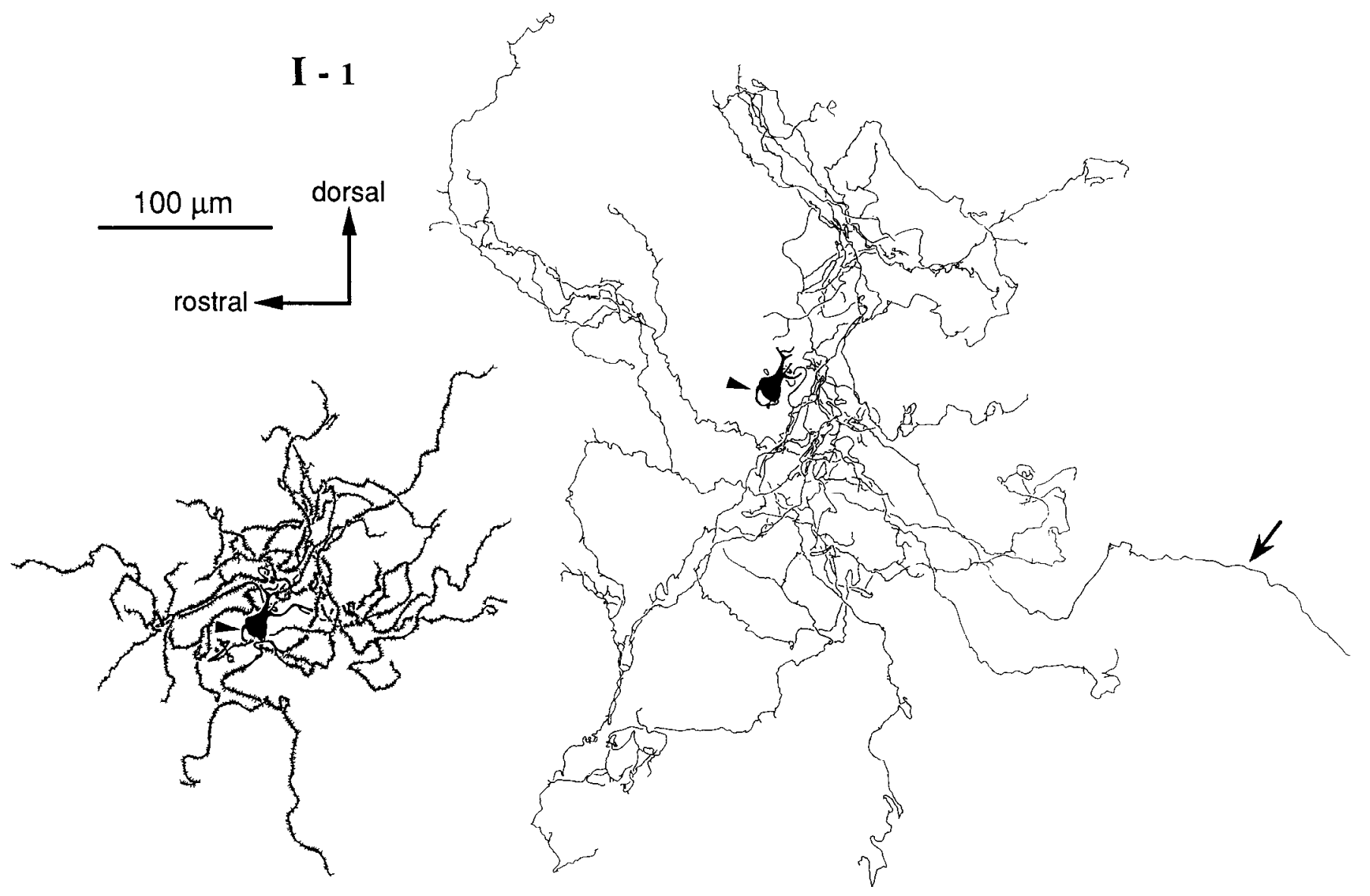

Figure 4. Reconstructed dendrites and axons distributed locally close to soma of type I cell (I-1). The origin of the axon is shown by the arrowhead. The main axonal branch is indicated by the arrow. Mediolateral spread of the dendrites ( 25 terminal branches) and local axons are $400 \mu \mathrm{m}$ and $800 \mu \mathrm{m}$, respectively.

restricted to the region around the parent dendrites; and (3) they could be positively identified as matrix cells using calbindin immunohistochemistry. They were collected throughout a large region of the NS, but mainly in the middle part of the NS dorsoventrally, where immunohistochemical staining of calbindin was strongest and compartmental boundaries were most clearly observed. These cells were categorized into 3 subtypes according to their branching patterns in the GP, EP, and SN pars reticulata. Type I cells projected only to the GP, while type II cells projected to the GP and SN. Furthermore, type II cells could be divided into 2 groups: type IIa cells, which had axon collateral branches to the EP as well as to the GP and SN, and type IIb cells, which did not. The locations of all the cells with restricted local axonal arborizations are shown in Figure 3.

Type I spiny-projection cells $(\mathrm{n}=4)$. Neurons whose axons project only to the GP are included in this category. An example showing the dendritic and local axonal field of a cell of this type is shown in Figure 4. The axonal arborization of the same cell in the GP is shown in Figure 5. The main axons of these cells were unbranched in their trajectory through the fiber fascicles toward the GP and branched to form axon collaterals at the border between the NS and the GP. The soma of the cell in Figures 4 and 5 (cell I-1) was situated in the dorsorostral part of the NS compared to the other 3 neurons (Fig. 3), and this cell had a single axonal arborization exclusively in the rostral half of the GP (Fig. 5). The pallidal axonal arborizations of the other 3 neurons of this type are shown in Figure 6. These neurons, located more caudally and closer to the boundary between the NS and GP, had 2 separate axonal arborizations in the GP. One of these was close to the boundary of the NS and the GP at the place where the axon penetrated the boundary, and the other was in the caudal half of the GP. This pattern is consistent with the organization of striopallidal fibers as observed in the previous study of single axons (Chang et al., 1981) and in axonal tracing experiments (Wilson and Phelan, 1982). Instead of entering the internal capsule, the axons of these cells curved away from the caudal boundary of the GP (Fig. 6).

Type IIa spiny-projection cells $(\mathrm{n}=5)$. Axons of this type reached the SN pars reticulata and gave off collateral branches in the EP. An example of the dendritic fields and local axon collateral fields of these neurons is shown in Figure 7. After giving off its initial collaterals, the axon of the cell shown in Figure 7 bifurcated in the fiber fascicles to form multiple axonal branches projecting to the GP and beyond. The branches of the axon of that cell are shown in the GP, EP, and SN in Figure 8. In other neurons of this type, the main axon did not bifurcate, and the entire axonal projections of each of the neurons arose from a single projecting branch. Otherwise, the axonal arborizations of the remaining 4 cells exhibited the same pattern of branching, as shown in Figure 9.

The axonal arborizations of type IIa neurons in the GP often showed multiple collateral arborizations arising at various levels 


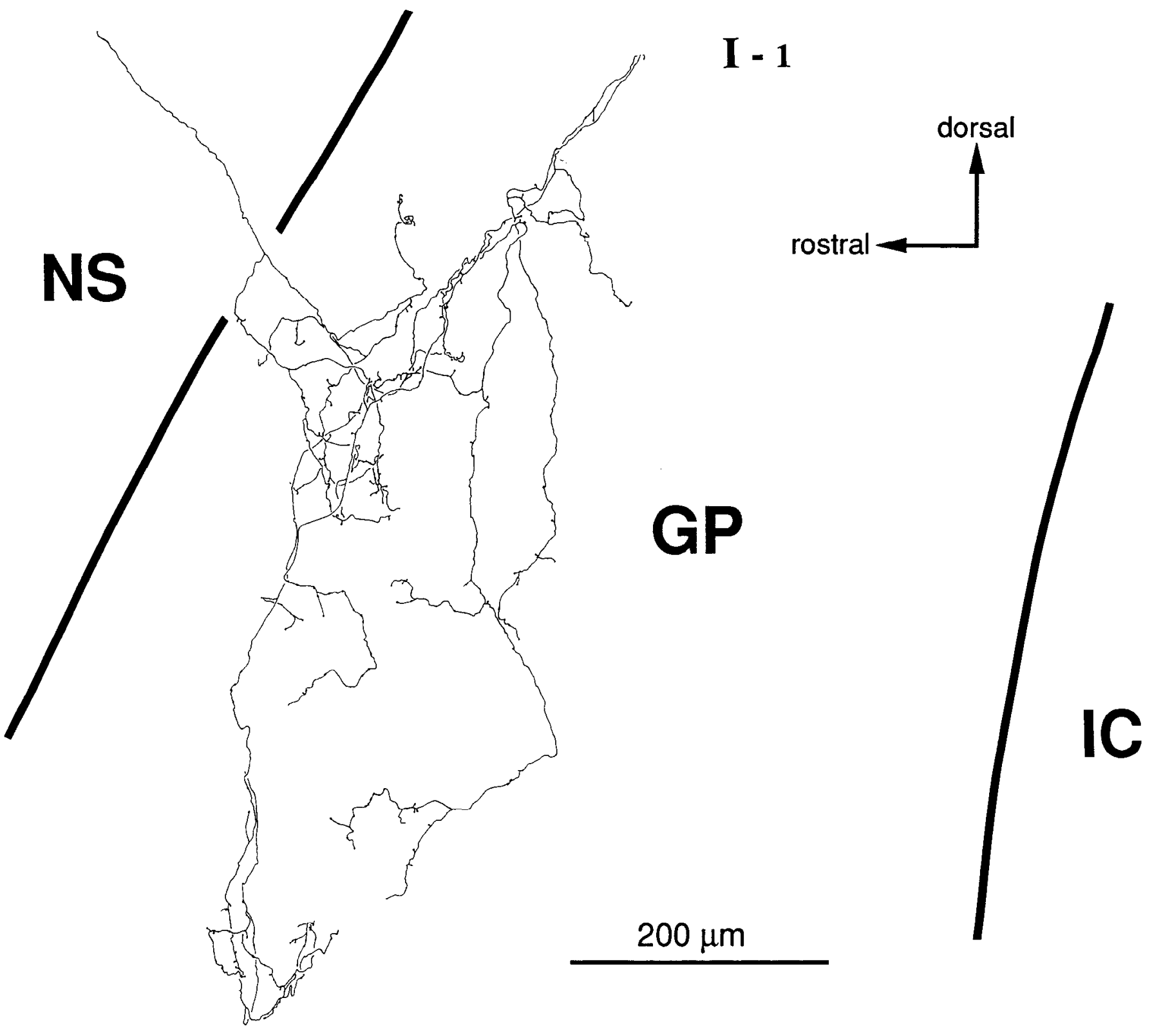

Figure 5. Axonal arborizations in the GP of type I cell (I-1). This cell was situated in the rostral part of the NS (see Fig. 3). The axonal ramifications were exclusively in the rostral part of the GP. Mediolateral spread of axon collaterals in the GP was $500 \mu \mathrm{m}$, and the arborization gave rise to 234 varicosities. IC, internal capsule.

in the GP. These usually grouped to form a rostral and caudal arborization (Fig. 9A-D). In the example in Figure 8, the arborization in the GP consisted of several short, vertically oriented, and relatively unbranched axon collaterals. Likewise, the projection to the EP consisted of several short and relatively simple collateral branches (Figs. 8, 9).

Type IIb spiny-projection cells $(\mathrm{n}=4)$. These cells had axons in the SN pars reticulata, but no branches in the EP. The dendritic tree of 1 of these cells and its axonal arborization are shown in Figures 10 and 11. All of these neurons exhibited axonal arborizations near the rostral border of the GP, but the remainder of the pallidal arborization varied from cell to cell according to the location of the neuron within the NS. This is shown in Figure 12. In the more caudally placed neurons of this type (cells IIb-1 and IIb-4), there was another axonal arborization near the caudal border of the GP as well. In both cases, the arborizations occurred close to the trajectories of the main axons in their courses through the GP. The staining in the SN was faint in all cases, but to the extent that the axons in this region could be visualized, they were located exclusively in the pars reticulata. One intracellular biocytin injection stained 2 cells and their axonal arborizations as far as SN (Fig. 12A, cells IIb-2, -3). We cannot determine whether this kind of multiple staining is due to an artifact or to the existence of gap junctions between the cells. In the case of these 2 neurons, however, it allows the examination of axonal arborizations of 2 neighboring neurons. As shown in Figure 12A, these 2 cells were both of type IIb and showed very similar axonal projections in the GP. 

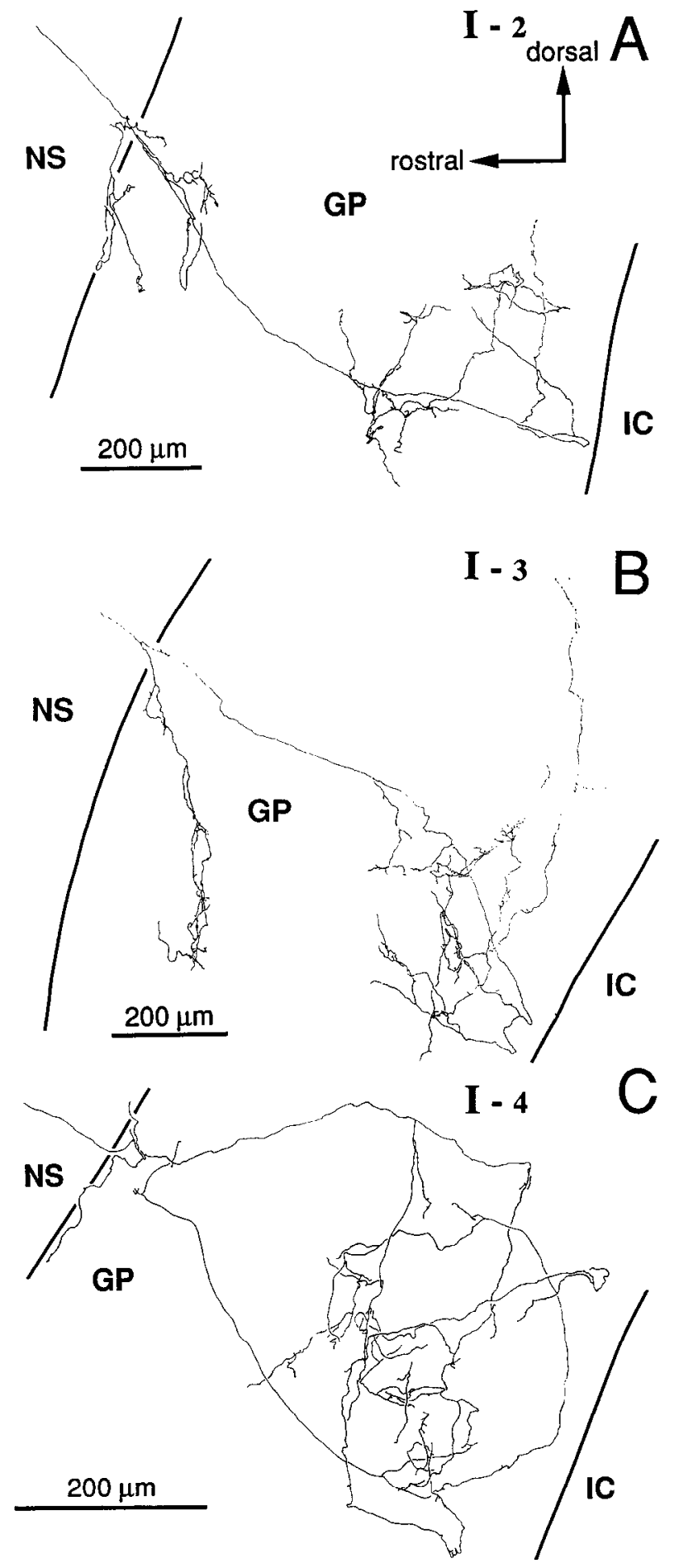

Figure 6. Axonal branching pattern of 3 type I cells $(A, \mathrm{I}-2 ; B, \mathrm{I}-3 ; C$, I-4). These cells were situated more caudally in the NS than the cell in Figure 5 (I-1). Axonal arborizations innervate both the rostral border and the caudal half of the GP. Each axon curves to avoid entering the internal capsule. Axons extend mediolaterally $400 \mu \mathrm{m}, 900 \mu \mathrm{m}$, and $600 \mu \mathrm{m}$ in $A, B$, and $C$, respectively. The number of varicosities in the GP are 192, 221, and 257 in $A, B$, and $C$, respectively. IC, internal capsule.

\section{Axonal arborizations in the globus pallidus}

All 3 classes of spiny-projection neurons have axonal branches in the GP. However, innervation patterns in the GP were different among these subtypes. Type I projection neurons had most widely distributed ramifications (Figs. 5, 6), while collaterals of type IIa and IIb cells were restricted in area and usually remained close to the main axons (Figs. 8, 9, 11, 12). The mediolateral spread of local collateral in the GP was also larger in type I cells (mean, $600 \mu \mathrm{m}$ ) than type IIa (mean, $387 \mu \mathrm{m}$ ) and IIb cells (mean, $500 \mu \mathrm{m}$ ). Boutons in the GP were most numerous in type I cells (mean, 226), with type IIa cells showing intermediate-sized arborizations (mean, 153) and IIb having the fewest axonal boutons (mean, 85) (Table 1). The common feature of axon collaterals in the GP is that main axons of every subtype issue collaterals just after entering the GP. There is a dorsoventral topography between the cellular location in the NS and the entering point into the GP. Because staining of axons in the SN was faint, we could not resolve the possibility of differences between type IIa and IIb cells in their branching in the SN pars reticulata.

\section{Somatodendritic morphology of the spiny cell subtypes}

The 3 spiny neuron subtypes identified by their axonal projections could not be distinguished on the basis of their somatodendritic morphology or the arborization patterns of their local axon collaterals. Their branching patterns, dendritic lengths, and dendritic spine densities were similar among the 3 subtypes. For example, we measured the spatial spread of dendrites and local axon collaterals and the number of terminal branches of dendrites from a type I cell (cell I-1), a type IIa cell (cell IIa-2), and a type IIb cell (cell IIb-1). The dendritic field ( 25 terminal branches) of the type I cell was $280 \mu \mathrm{m}$ rostrocaudally, $290 \mu \mathrm{m}$ dorsoventrally, and $400 \mu \mathrm{m}$ mediolaterally. The local axon collaterals of the type I cell spread $400 \mu \mathrm{m}$ rostrocaudally, $490 \mu \mathrm{m}$ dorsoventrally, and $800 \mu \mathrm{m}$ mediolaterally. Dendritic extent for the type IIa cell (23 terminal branches) was $210 \mu \mathrm{m}$ rostrocaudally, $240 \mu \mathrm{m}$ dorsoventrally, and $250 \mu \mathrm{m}$ mediolaterally. This type IIa cell had local axons arborizing $340 \mu \mathrm{m}$ rostrocaudally, $320 \mu \mathrm{m}$ dorsoventrally, and $400 \mu \mathrm{m}$ mediolaterally. Spread of the dendritic field for the type IIb cell (36 terminal branches) was $350 \mu \mathrm{m}$ rostrocaudally, $310 \mu \mathrm{m}$ dorsoventrally, and 350 $\mu \mathrm{m}$ mediolaterally, while the local axonal arborization of that cell occupied a volume reaching approximately $500 \mu \mathrm{m}$ rostrocaudally, $480 \mu \mathrm{m}$ dorsoventrally, and $500 \mu \mathrm{m}$ mediolaterally.

\section{Matrix spiny cells with local axons distributed widely in the neostriatum}

We found 2 cells with local axon collaterals widely distributed within the NS. One of these was identified as a matrix projection cell by counterstaining with calbindin immunocytochemistry and by following its axon to the GP. A cell of this type was first reported by Bishop et al. (1982), and their existence in the NS matrix was recently confirmed by Kawaguchi et al. (1989a). A reconstruction of the soma and dendrites of the better-characterized neuron of this type is shown in Figure 13. There were no apparent somatodendritic morphological differences between the 2 cells of this type and the neurons with local axonal arborizations distributed close to the parent dendritic domain. The spatial spread of dendrites of the cell in Figure 13 (22 terminal branches) was $250 \mu \mathrm{m}$ rostrocaudally, $400 \mu \mathrm{m}$ dorsoventrally, and $250 \mu \mathrm{m}$ mediolaterally, múking it approximately the same as the other cells collected in these experiments. Its local axonal arborization is shown in Figure 14. It differed dramatically from those of other spiny neurons, extending 1650 $\mu \mathrm{m}$ rostrocaudally, $1080 \mu \mathrm{m}$ dorsoventrally, and $1100 \mu \mathrm{m}$ mediolaterally. The intrastriatal axonal collaterals of these cells 


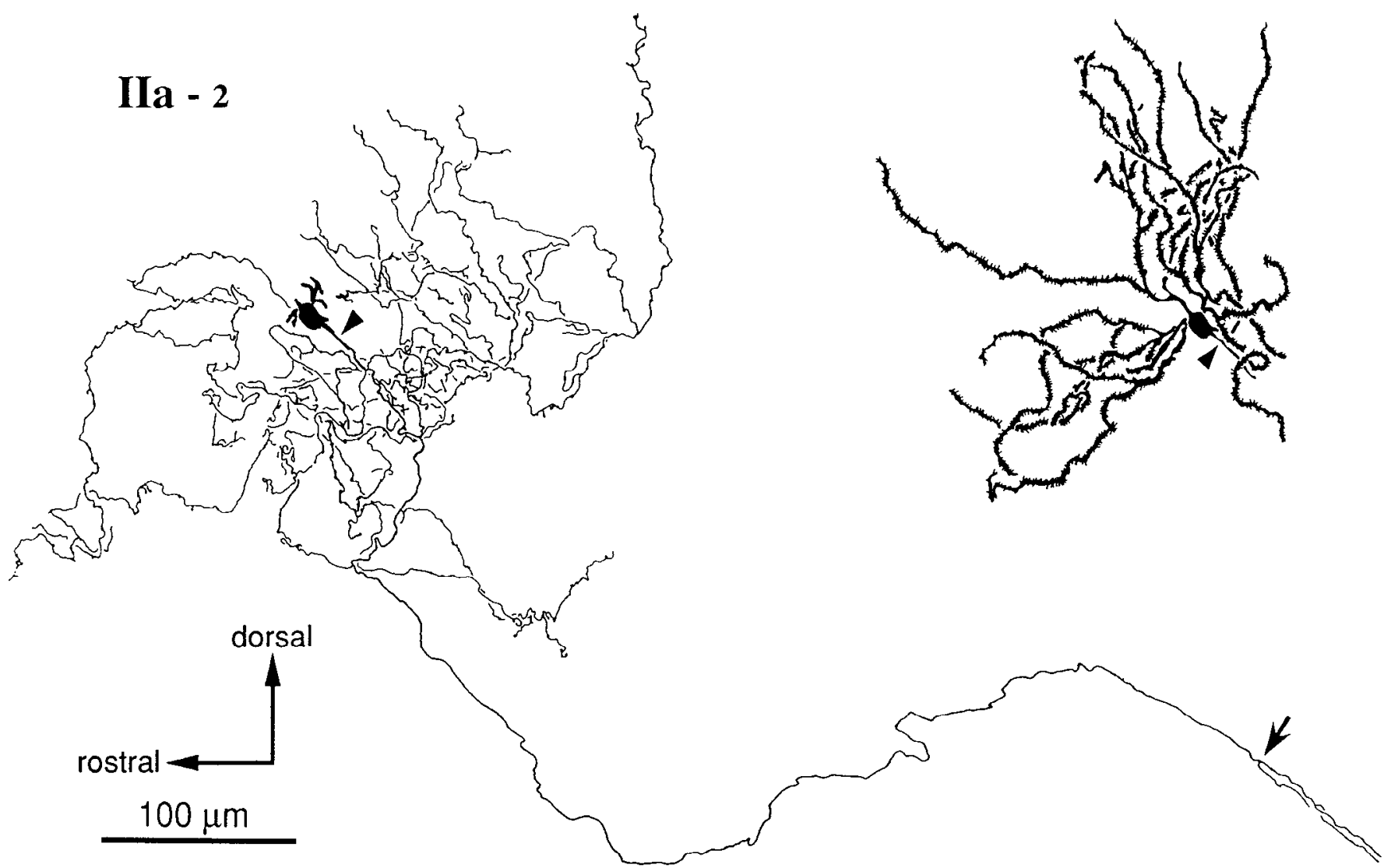

Figure 7. Reconstruction of dendrites and local axon collaterals of same type IIa cell (IIa-2) shown in Figures 1 and 2 . Branching dendrites are densely spined, and local axon collaterals are close to the dendrites. There are 23 terminal dendritic branches, and the mediolateral spread of the dendrites and local axons is $250 \mu \mathrm{m}$ and $400 \mu \mathrm{m}$, respectively. Mediolateral spread was estimated from the number of 50- $\mu \mathrm{m}$ sections containing dendrites or axon collaterals. The main axon originates at the point shown by the arrowhead and bifurcates in the internal capsule bundle (arrow).

formed a network surrounding the parent dendritic field, but did not arborize within the dendritic field of the parent cell. The main axon of the neuron that could be followed out of the NS was unbranched in the internal capsule fascicles. Like the axons of the other spiny-projection neurons, collateral branches from the axon of this cell diverged from the main axon at the border between the NS and the GP. Because the staining of the axon of this cell faded relatively rapidly within the GP, it could not be followed further, and it could not be determined whether or not this axon had projections to the EP or SN.

\section{Discussion}

Biocytin as an intracellular maker for in vivo studies of axonal projections

Previous studies of axonal arborizations of spiny neurons (Preston et al., 1980; Chang et al., 1981) have demonstrated the existence of at least 2 different kinds of spiny-cell axonal pro- jections to the GP in the rat. One kind of axon seen in those studies passed through the GP, often emitting collaterals in passage through the structure. The other type of axon was seen to make more extensive arborizations in the GP (Chang et al., 1981). Because of the limitations of the intracellular HRP technique, it was never possible to establish the absence of an axonal branch. Therefore, it was impossible to tell whether the axons that appeared to pass through the GP without arborizing there actually did such, or whether they emitted small axon collaterals that were too faint to detect. Likewise, the axons that arborized extensively in the GP could not be traced to more caudal structures, but their axons were very faintly stained at the caudal border of the GP. It was not clear whether or not they had branches making connections with more caudal structures. These shortcomings were overcome by use of the biocytin technique developed by Horikawa and Armstrong (1988). We could trace the complete local axonal arborization and nearly all of the

Table 1. Number of boutons and mediolateral spread of collaterals in the GP

\begin{tabular}{lllc} 
& Type I $(n=4)$ & Type IIa $(n=5)$ & Type IIb $(n=4)$ \\
\hline Number of boutons & $226 \pm 27(192-257)$ & $153 \pm 41(116-212)$ & $85 \pm 12(70-99)$ \\
Mediolateral spread $(\mu \mathrm{m})$ & $600 \pm 216(400-900)$ & $387 \pm 110(300-550)$ & $500 \pm 71(450-600)$ \\
\hline
\end{tabular}



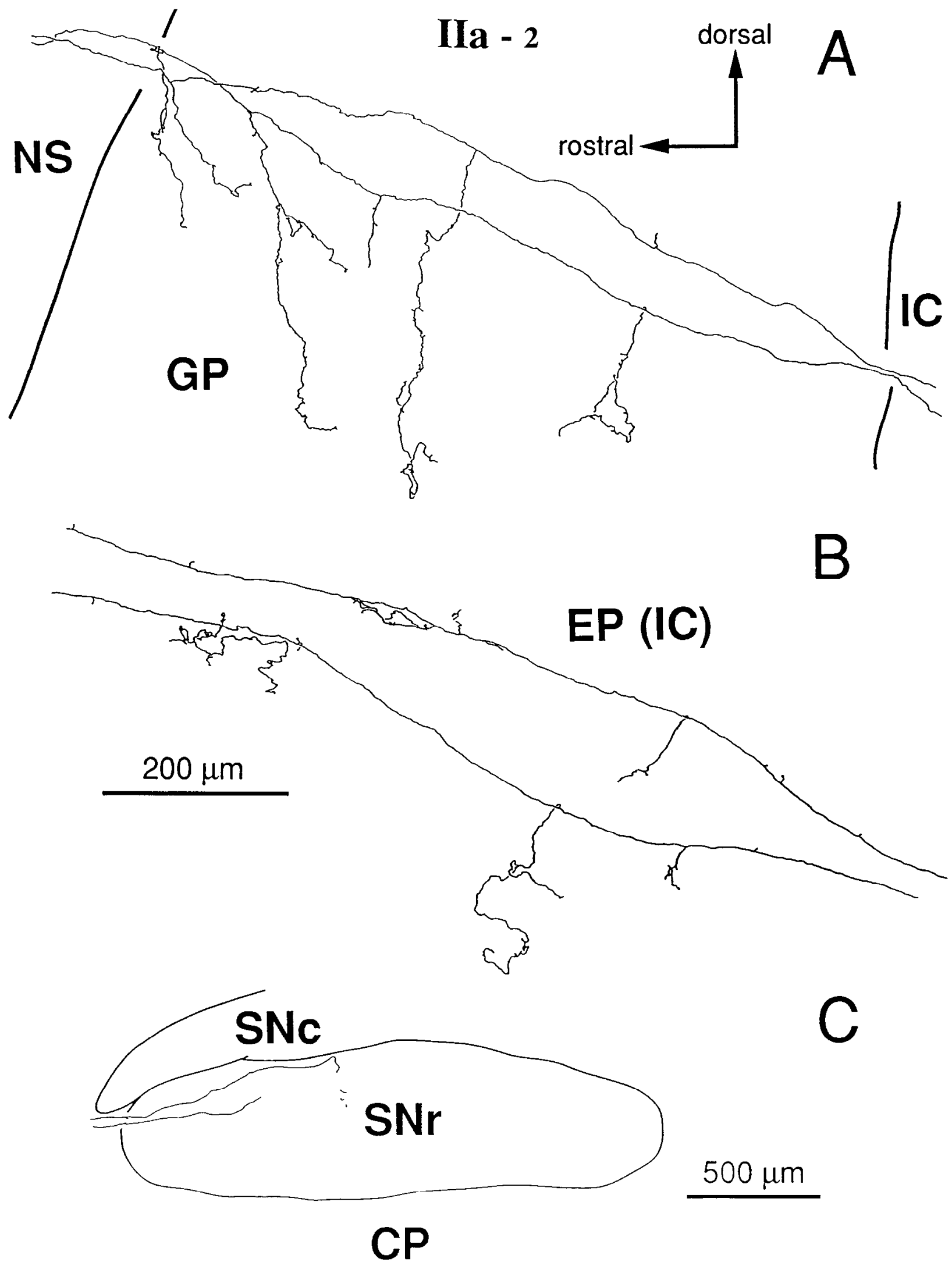

Figure 8. Axon collateral arborizations in GP, EP, and SN of same cell (IIa-2) shown in Figures 1, 2, and 7. A, The 2 main axonal branches enter the GP and follow similar trajectories. The axon collaterals spread over a $500-\mu \mathrm{m}$ region in the GP mediolaterally and formed 116 axonal varicosities. $B$, Branching pattern in the EP is also similar for the 2 axonal branches. The EP is embedded in the internal capsule. $C$, Both axons enter the SN pars reticulata, but their staining became too faint to draw the axonal arborization. $A$ has the same magnification as $B$. CP, cerebral peduncle; IC, internal capsule; SNc, substantia nigra pars compacta; $\mathrm{SNr}$, substantia nigra pars reticulata. 
efferent axonal arborization, at least as far as the $\mathrm{SN}$, with confidence that nothing was missed. Previous work has established the superiority of biocytin in reliability of staining and in electrode properties, which has made it attractive for use in physiological studies of neurons in tissue slices (Horikawa and Armstrong, 1988). The advantages of biocytin in staining large axonal arborizations is not apparent in tissue slices, however, so they have gone mostly unnoticed. The improved staining of axons obtained with biocytin may be due to its small molecular weight and high solubility, which may improve its mobility in the electrode and increase the amount of tracer that can be injected into a neuron, and may also increase its diffusion rate within the cell. It may also be partly due to the high sensitivity of the avidin-biotin detection method employing avidin biotinylatedHRP complex (Hsu et al., 1981).

\section{Neostriatal cell types and long-range axonal projection patterns}

NS projection neurons have been suggested to consist of 2 major classes on the basis of target structure as seen in retrograde labeling studies (Feger and Crossman, 1984; Parent et al., 1984; Loopuijt and van der Kooy, 1985; Beckstead and Cruz, 1986). One of these projects preferentially to the GP (external segment), and one projects to the EP (or GP internal segment) and SN. The simplest interpretation of these observations would be that there are 2 mutually exclusive sets of striatal projection neurons, 1 projecting to the GP only (and enkephalin-positive), and 1 projecting to the EP and SN (and staining with antibodies to substance $P$ and dynorphin). This simple scheme has already been experimentally eliminated in rats. Chang et al. (1981) reported that axons of striatonigral ncurons identified by antidromic activation sometimes gave off collaterals in the GP that terminated in that structure, though the arborizations of these neurons were small compared to those projecting primarily to the GP. The existence of neurons with axons branching to both the $\mathrm{SN}$ and the GP in the rat was also demonstrated by Loopuijt and van der Kooy (1985), using retrograde double labeling. Their study suggested that about $40 \%$ of neurons projecting to the SN also projected to the GP. From such data, it is not possible to know if some neurons project only to GP, while others project to both the GP and the SN, or if there are special cell populations that go to each structure exclusively and a third that branches to both. There are even less data on branching of axons to the EP and GP or to the EP and SN. On the basis of their neurophysiological observations, Yoshida et al. (1972) suggested that some or all nigrostriatal axons also project to the EP, but anatomical studies have not followed up on this suggestion for technical reasons.

The results we have obtained using single axonal arborizations are summarized in Figure 15. This figure shows only what has been revealed using single-neuron labeling. Much has been revealed of the projections of patch neurons using retrograde labeling techniques, but the arborization patterns of individual neurons are not revealed by that method, so this information is not included. Single-neuron staining has so far been applied to only a subset of the striatal-projection neurons, those of the calbindin-rich matrix compartment. This is not a severe restriction, because the matrix makes up approximately $90 \%$ of the rat NS (e.g., Johnston et al., 1988). The density of spiny-projection neurons is approximately the same in both compartments, making approximately $90 \%$ of all spiny neurons matrix cells. Of matrix neurons, we know least about the cells with large intrastriatal axonal arborizations, because our sample of these neurons is so small. Some of them, at least, project to the GP. Much more can be said about the projections of matrix spiny neurons with restricted intrastriatal arborizations. Among our sample of these neurons all contributed some axonal collaterals to the neuropil of the GP. Of the 7 possible branching patterns (GP only, SN only, EP only, GP+SN, GP+EP, SN+EP, $\mathrm{GP}+\mathrm{EP}+\mathrm{SN})$, only 3 were observed $(\mathrm{GP}$ only, GP+SN, $\mathrm{GP}+\mathrm{EP}+\mathrm{SN})$. This finding is consistent with all of the published neurophysiological, immunocytochemical, or retrograde tracing data. The finding of Yoshida et al. (1972), that a large proportion, perhaps all, of the striatal projections to the EP arise from neurons that also project to the $\mathrm{SN}$, is confirmed by our results. Although double-labeled neurons have been seen in all fluorcscent retrograde tracing studies of the striatal efferents, they have usually been reported as minor (Beckstead and Cruz, 1984; Feger and Crossman, 1984; Parent et al., 1984; Loopuijt and van der Kooy, 1985). This is usually interpreted to mean that there are few branching neurons, but it could instead be interpreted to mean that the GP axonal arborizations of branching neurons are small or sparsely branched and so go largely undetected in double-fluorescence-labeling studies. The GP terminal fields of neurons projecting to the SN fill a much smaller volume of the GP and contain fewer boutons than those projecting to the GP alone. Retrograde staining of such neurons would be much more sensitive to position of the injection site than neurons with more extensive and branched arborizations. In addition, the presence of a smaller uptake surface may result in less intense retrograde staining. Some double-labeled neurons were reported in most of the published studies using retrograde tracing from the GP and SN. These were often particularly abundant in those parts of the NS where single-labeled neurons from the 2 injection sites were intermingled (e.g., Parent et al., 1984). These findings indicate that, in the cat and primate, as in the rat, a significant number of double-labeled neurons can be observed in these studies when the topographical relationship between the injection sites is most favorable for detecting them. Likewise, though enkephalin immunoreactivity is most concentrated in the GP and substance P immunoreactivity is strongest in the SN and EP, both substances can be detected in fibers in all 3 nuclei. The most likely interpretation is that our type I cells are the enkephalin-positive neurons of the matrix, while our type IIa and type IIb cells contain substance P and dynorphin. The similarity of somatodendritic features of these cell types is consistent with the findings of Izzo et al. (1987) that enkephalin- and substance P-immunoreactive neurons in the NS share a single somatodendritic phenotype.

The absence of some other of the possible cell types is provocative. While there were neurons that projected to the $\mathrm{SN}$ but not to the EP, we did not find neurons projecting to the EP but not the SN. Of course, the limited size of the sample of neurons available using intracellular staining does not allow us to rule out the existence of neurons with these projection patterns. Therefore, such neurons may exist in the matrix compartment, but their absence in our sample suggests that they are not common.

Chang et al. (1981) observed a relationship between the axonal projections of NS neurons and the branching of their axons within the internal capsule bundles enroute to the GP. Neurons in their sample that branched extensively in the GP (corresponding most closely to the type I neurons of this study) exhibited axonal branching in the fiber fascicles, while axons con- 


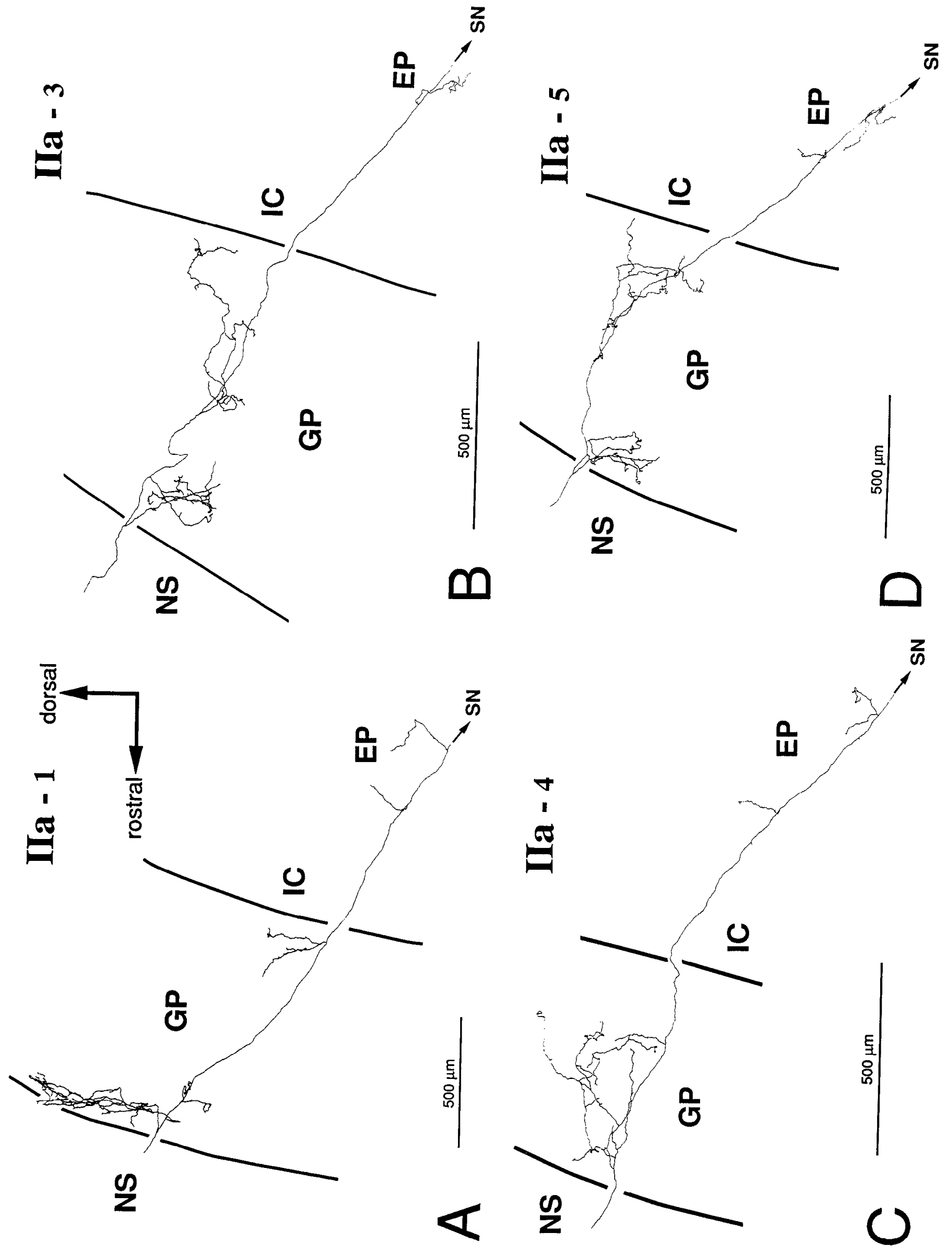




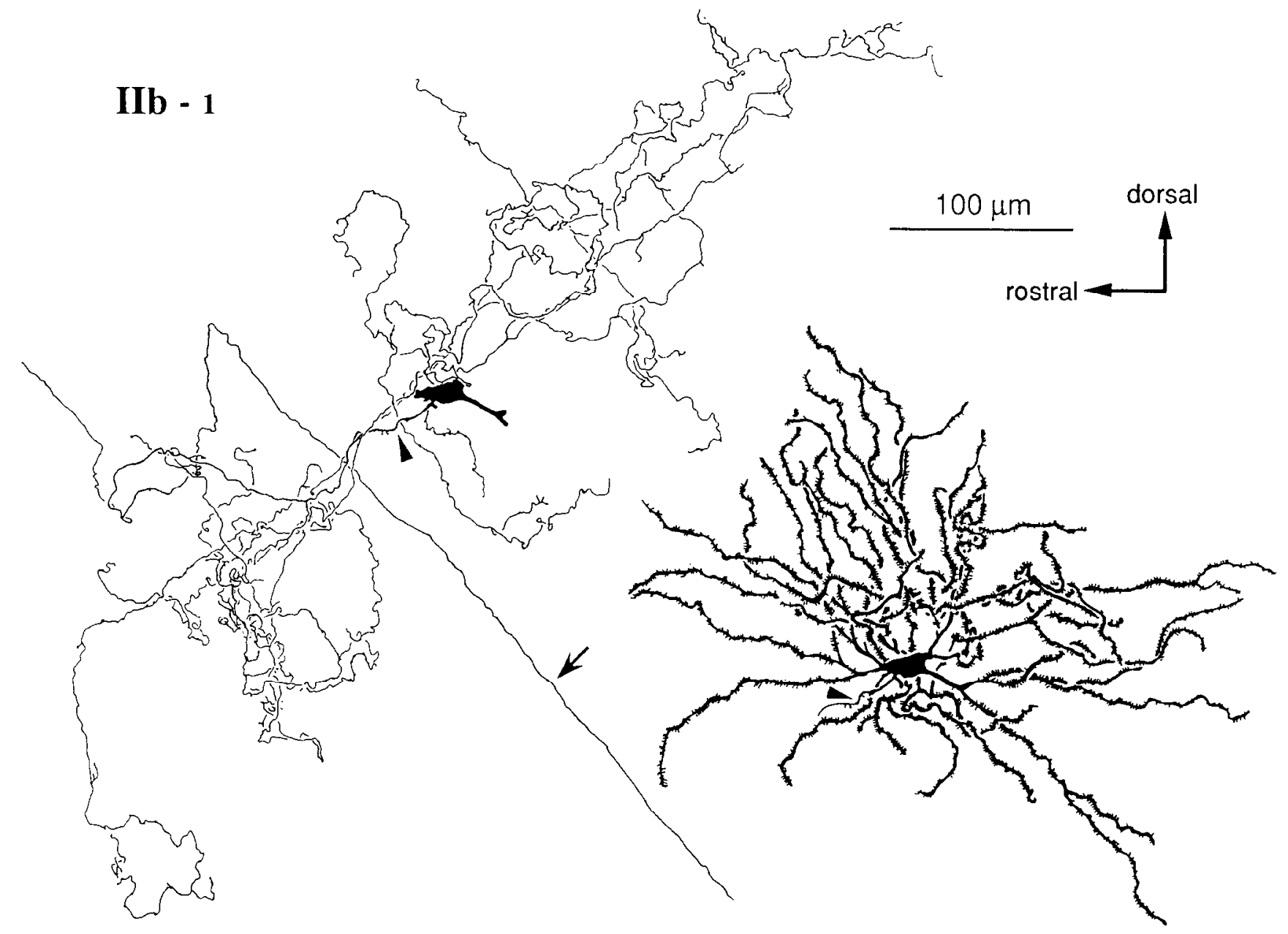

Figure 10. Reconstructed dendrites and local axons of type IIb cell (IIb-1). The dendrites and local axons extend mediolaterally $350 \mu \mathrm{m}$ and 500 $\mu \mathrm{m}$, respectively. The axon origin is indicated by the arrowhead, and the main axon by the arrow.

tributing few collaterals to the GP (like the type II cells of this study) did not. In the present sample, we could find only 1 neuron whose main axon branched within the fiber fascicles. Although we cannot explain this difference between our sample and that of Chang et al. (1981), it could reflect differences in the axonal branching of neurons located in different positions within the NS. Because of the short range of axonal staining with HRP, those authors were restricted to the study of NS neurons close to the border with the GP. Neurons in the present study were located in the central region of the NS. The present results indicate that classes of NS projection neurons differing in axonal projections cannot be reliably identified by the existence of axonal branches in the internal capsule fascicles.

\section{Coll clustering of the same projection subtypes in the matrix}

Multiple-labeled cells observed after biocytin injection both in this study and in a previous one (Kawaguchi et al., 1989a) were found to belong to the same compartment. In this study, such cells were found to be of the same projection subtype and to have similar axon trajectories and overlapping fields of arborization. This suggests the possibility that similar projection neurons in the same compartment form small clusters that represent another dimension of spatial organization within the patches and matrix. Recent retrograde-labeling studies also suggest this kind of compartmentalization (Loopuijt and van der Kooy, 1985; Jimenez-Castellanos and Graybicl, 1989). Loopuijt and van der Kooy (1985) reported that, in rats, the cells projecting only to the GP or to the SN tended to cluster, while cells projecting to both tended not to do so. Their cells projecting only to the GP and only to the SN may correspond to type I and type IIb cells respectively, because type IIb cells have the least boutons among subtypes and have been found to cluster (Fig. 12). Type IIa cells (projecting to all neostriatal targets) may therefore be distributed uniformly within the NS.

According to Loopuijt and van der Kooy (1985), the clusters are approximately $100 \mu \mathrm{m}$ long and $50 \mu \mathrm{m}$ wide. The scale of

Figure 9. Axonal branches in GP and EP of 4 type IIa cells ( $A$, IIa-1; $B$, IIa-3; $C$, IIa-4; $D$, IIa-5). Unlike the cell shown in Figure 8 , the main axonal branches of these cells were unbranched in the internal capsule. In the GP, they formed 2 regions of arborization. One was along the border between the NS and the GP, and the other varied in position depending upon the location of the neuron in the NS. The axons extended mediolaterally $350 \mu \mathrm{m}, 300 \mu \mathrm{m}, 350 \mu \mathrm{m}$, and $550 \mu \mathrm{m}$ in the GP in $A, B, C$, and $D$, respectively. Varicosities arising from collaterals in the GP were 212 , 130 , 130, and 179 in number in $A, B, C$, and $D$, respectively. Collateral branches in the EP were few compared to those in the GP. IC, internal capsule. 


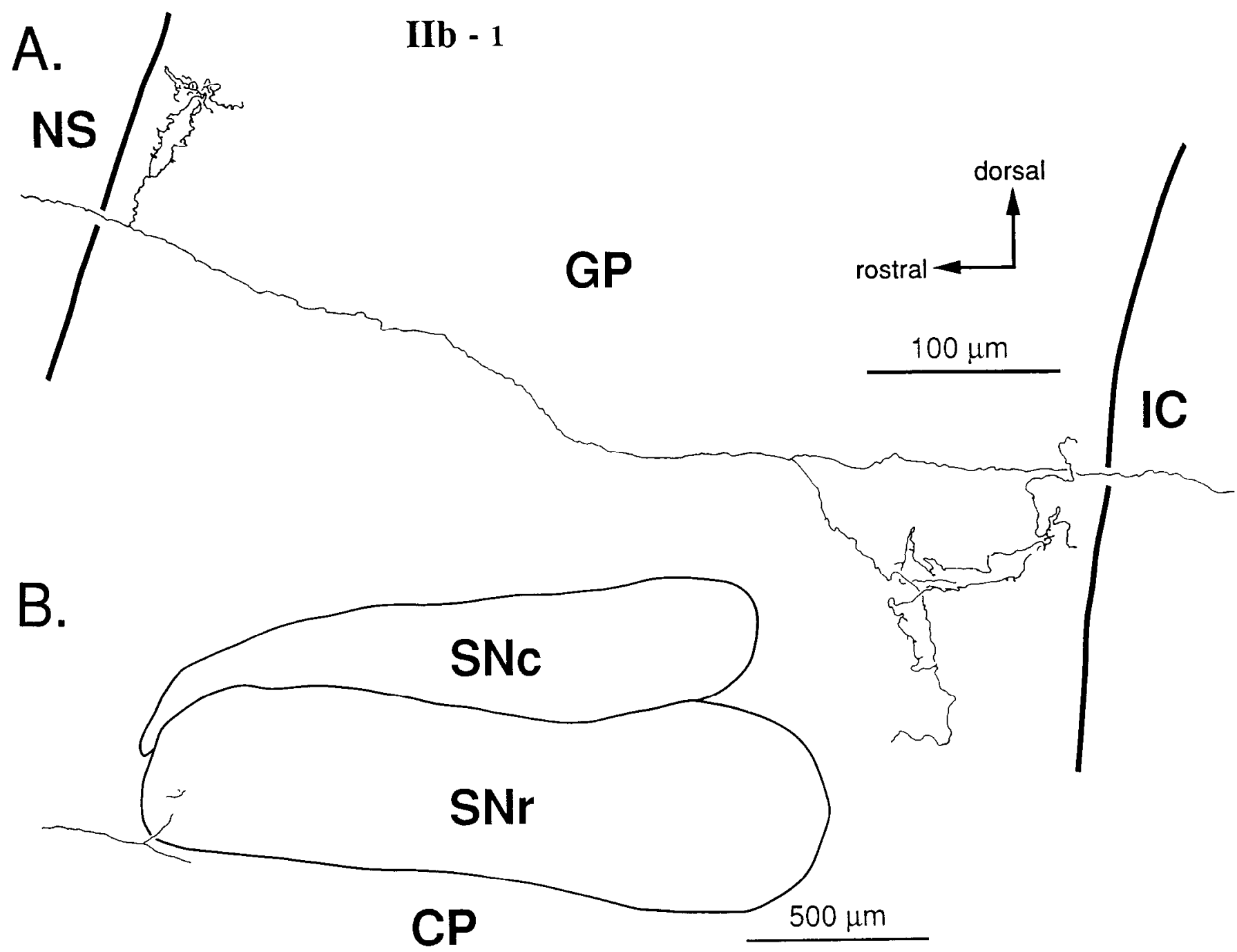

Figure 11. Axonal arborization of type IIb cell (IIb-1) in the GP. This is the same cell as shown in Figure 10. A, Collateral branches formed at the rostral and caudal border of the GP. The collaterals extended mediolaterally for $600 \mu \mathrm{m}$. $B$, The main axon entered the SN pars reticulata from the rostroventral side. $\mathrm{CP}$, cerebral peduncle; IC, internal capsule; SNc, substantia nigra pars compacta; $\mathrm{SNr}$, substantia nigra pars reticulata.

these clusters is therefore much smaller than that of dendrites and local axonal arborizations, allowing for a high degree of interconnectivity between cells in different clusters.

The pattern of local axon collaterals within the NS can divide matrix projection neurons into 2 classes

We have confirmed the existence of 2 types of medium-sized spiny neurons that can be distinguished on the basis of the pattern of arborization of their local axon collaterals, as originally described by Bishop et al. (1982). One group of neurons has intrastriatal axonal arborizations overlapping with or adjacent to the dendritic field of the parent cell. This kind of cell is by far the more common. The other, less common type of cell has much larger and more extended axonal arborizations that go far beyond, and often do not overlap, the dendritic domain of the cell. This type was first described by Bishop et al. (1982) and was recently reported to be contained (axons and dendrites, as well as somata) within in the matrix compartment (Kawaguchi et al., 1989a). Bishop et al. (1982) reported that their single example of a cell of this type had a somewhat lower density of dendritic spines than other spiny neurons. The den- dritic spine densities of the neurons of this type in the present sample and those of the previous paper (Kawaguchi et al., 1989a) were indistinguishable from other spiny neurons. Spiny neurons exhibit a wide range of spine densities (e.g., Wilson et al., 1983c), and probably the low spine density of the neuron reported by Bishop et al. (1982) was duc to this variation rather than a property of cells with extended intrastriatal axonal arborizations.

The volume occupied by the intrastriatal axonal arborization of this cell type is even greater than previously suspected. Intracellular staining with HRP probably failed to demonstrate the entire arborization, and of course, the most distant axonal branches were cut of in the neurons stained in NS tissue slices. The examples obtained in this study show axon collateral fields extending over a $1-\mu \mathrm{m}$ diameter, making them as large or larger than the axonal arborization of the giant aspiny NS interneuron (Wilson et al., 1990).

\section{Neuronal cell types based on axonal projections}

It has long been recognized that the somatodendritic morphology of neurons is insufficient for the recognition of functional 

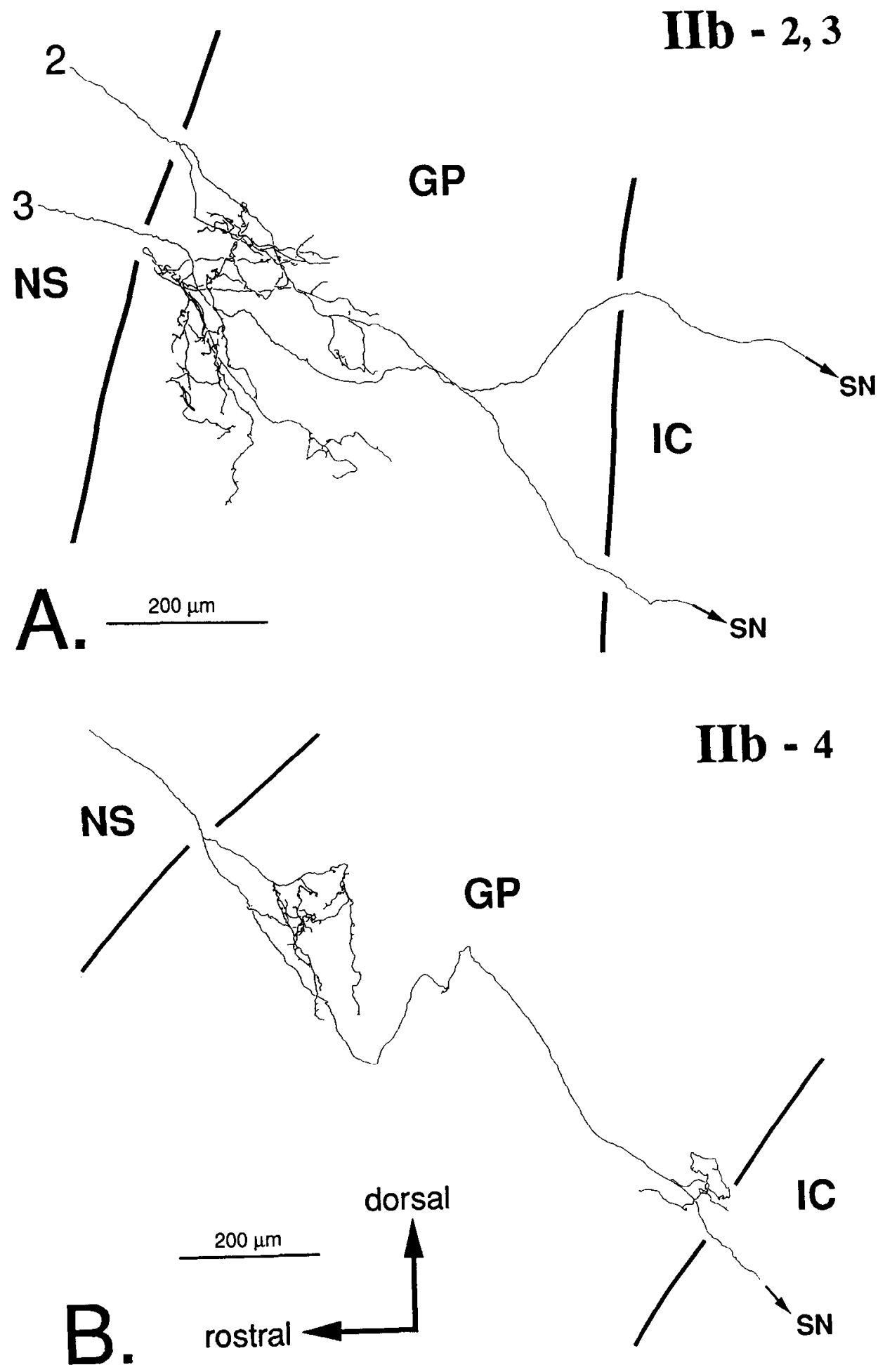

Figure 12. Axonal arborizations of 3 type IIb cells in GP. $A$, Two axons coming from 2 different neurons stained by the same biocytin injection (IIb-2 and IIb-3) and forming similar axonal arborizations in the GP. The collaterals extended mediolaterally for $450 \mu \mathrm{m}$ and $500 \mu \mathrm{m}$, respectively. Varicosities were 99 and 83 in number respectively. $B$, The axon of another type IIb cell (IIb4) that issued collaterals at both the rostral and caudal borders of the GP. IC, internal capsule.

cell types in many brain structures. Nowhere is this more apparent than in the NS, where immunocytochcmical techniques have almost completely supplanted morphological ones for the identification and even the definition of cell types. Axonal morphology, and especially the pattern of long-range connections of neurons, is generally recognized as required for any complete system for the identification of functionally important subpopulations of cells. In the NS, axonal-projection patterns are ap- parently a more discriminating indicator than dendritic morphology in distinguishing the function categories of spinyprojection neurons. The technical difficulty in examining the complete axonal field of individual neurons, starting with the problems with axonal staining using the Golgi method and continuing with more modern cytochemical and immunocytochemical methods, has been the reason axonal fields have not been more commonly used for identification of cells. One exception 


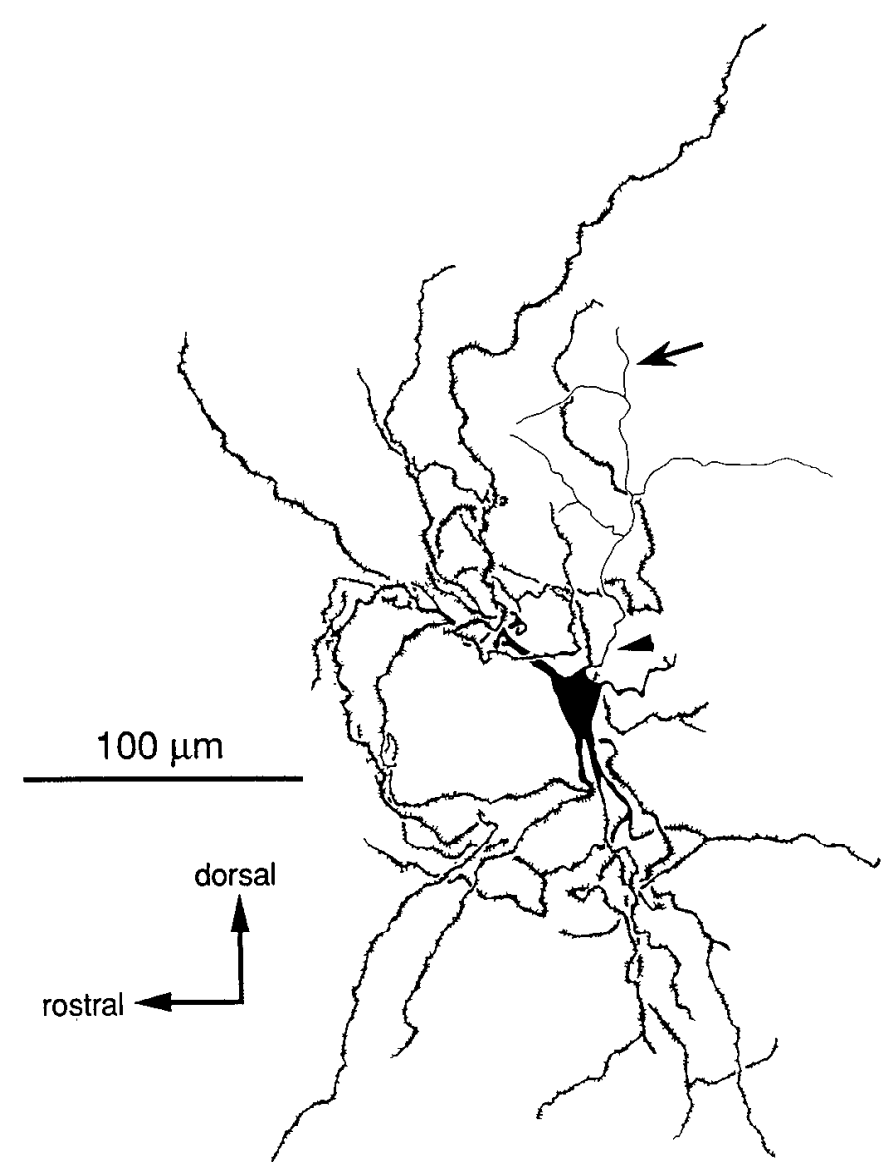

Figure 13. Reconstruction of dendritic field of cell with widespread intrastriatal axonal arborization. Origin of the axon is shown at the arrowhead. The arrow points at the axons. Dendritic terminal branches $(n=22)$ extend mediolaterally for $250 \mu \mathrm{m}$.

has been the success of the intraaxonal staining method, but this has been restricted to axons of sufficient calibcr to allow impalement with microelectrodes. Improvements in axonal staining from intrasomatic injections, as employed here, may soon make this kind of analysis routine for all kinds of neurons.

\section{References}

Beckstead RM, Cruz JC (1986) Striatal axons to the globus pallidus, entopeduncular nucleus and substantia nigra come mainly from separate cell populations in cat. Neuroscience 19:147-158.

Beckstead RM, Kersey KS (1985) Immunohistochemical demonstration of differential substance-P, met-enkephalin- and glutamic-aciddecarboxylase-containing cell body and axon distributions in the corpus striatum of the cat. J Comp Neurol 232:481-498.

Bishop GA, Chang HT, Kitai ST (1982) Morphological and physiological properties of neostriatal neurons: an intracellular horseradish peroxidase study in the rat. Neuroscience 7:179-191.

Brand S, Rakic P (1984) Cytodifferentiation and synaptogenesis in the neostriatum of fetal and neonatal rhesus monkeys. Anat Embryol 169:21-34

Chang HT, Wilson CJ, Kitai ST (1981) Single neostriatal efferent axons in the globus pallidus: a light and electron microscopic analysis. Science 213:915-918.

Chesselet M-F, Graybiel AM (1983) [Met]enkephalin-like and dynorphin-like immunoreactivities of the basal ganglia of the cat. Life Sci 33:37-40.

Donoghue JP, Herkenham M (1986) Neostriatal projections from individual cortical fields conform to histochemically distinct striatal compartments in the rat. Brain Res 365:397-403.

Feger J, Crossman AR (1984) Identification of different subpopula- tions of neostriatal neurones projecting to globus pallidus or substantia nigra in the monkey: a retrograde fluorescence double-labelling study. Neurosci Lett 49:7-12.

Gerfen CR (1984) The neostriatal mosaic: compartmentalization of corticostriatal input and striatonigral output systems. Nature 311: 461-464.

Gerfen CR (1985) The neostriatal mosaic. I. Compartmental organization of projections from the striatum to the substantia nigra in the rat. J Comp Neurol 236:454-476.

Gerfen CR, Young WS III (1988) Distribution of striatonigral and striatopallidal peptidergic neurons in both patch and matrix compartments: an in situ hybridization histochemistry and fluorescent retrograde tracing study. Brain Res 460:161-167.

Gerfen CR, Baimbridge KG, Miller JJ (1985) The neostriatal mosaic: compartmental distribution of calcium binding protein and parvalbumin in the basal ganglia of the rat and monkey. Proc Natl Acad Sci USA 82:8780-8784.

Graybiel AM, Hickey TL (1982) Chemospecificity of ontogenetic units in the striatum: demonstration by combining $\left[{ }^{3} \mathrm{H}\right]$-thymidine neuronography and histochemical staining. Proc Natl Acad Sci USA 79: 198-202.

Graybiel AM, Ragsdale CW, Moon Edley S (1979) Compartments in the striatum of the cat observed by retrograde cell labeling. Exp Brain Res 34:189-195.

Horikawa H, Armstrong WE (1988) A versatile means of intracellular labeling: injection of biocytin and its detection with avidin conjugates. J Neurosci Meth 25:1-11.

Hsu SM, Raine L, Fanger H (1981) The use of avidin-biotin-peroxidase complex $(\mathrm{ABC})$ in immunoperoxidase techniques: a comparison between ABC and unlabeled antibody (PAP) procedures. J Histochem Cytochem 29:577-580.

Izzo PN, Graybiel AM, Bolam JP (1987) Characterization of substance P- and [met]enkephalin-immunoreactive neurons in the caudate nucleus of cat and ferret by a single section Golgi procedure. Neuroscience 20:577-587.

Jimenez-Castellanos J, Graybiel AM (1989) Compartmental origins of striatal efferent projections in the cat. Neuroscience 32:297-321.

Johnston JG, Gerfen CR, Andruschak K, Haber S, van der Kooy D (1988) Striatal compartmentalization is precisely preserved across the mammalian order. Soc Neurosci Abstr 14:76.

Kanazawa I, Emson PC, Cuello AC (1977) Evidence for the existence of substance-P containing fibers in striato-nigral and pallido-nigral pathways in rat brain. Brain Res 119:447-453.

Kawaguchi Y, Wilson CJ, Emson PC (1989a) Intracellular recording of identified neostriatal patch and matrix spiny cells in a slice preparation preserving cortical inputs. J Neurophysiol 62:1052-1068.

Kawaguchi Y, Wilson CJ, Emson PC (1989b) Axonal projection patterns of identified neostriatal matrix spiny cells revealed by intracellular injection of biocytin in rats. Soc Neurosci Abstr 15:909.

Kitai ST, Kocsis JD, Preston RJ, Sugimori M (1976) Monosynaptic inputs to caudate neurons identified by intracellular injection of horseradish peroxidase. Brain Res 109:601-606.

Loopuijt LD, van der Kooy D (1985) Organization of the striatum: collateralization of its efferent axons. Brain Res 348:86-99.

Parent A, Bouchard C, Smith Y (1984) The striatopallidal and striatonigral projections: two distinct fiber systems in primate. Brain Res 303:385-390.

Penny GR, Afsharpour S, Kitai ST (1986) The glutamate decarboxylase-leucine enkephalin-, methionine enkephalin- and substance Pimmunoreactive neurons in the neostriatum of the rat and cat: evidence for partial overlap. Neuroscience 17:1011-1045.

Penny GR, Wilson CJ, Kitai ST (1988) Relationship of the axonal and dendritic geometry of spiny projection neurons to the compartmental organization of the neostriatum. J Comp Neurol 269:275289.

Preston RJ, Bishop GA, Kitai ST (1980) Medium spiny neurons projection from the rat striatum: an intracellular horseradish peroxidase study. Brain Res 185:253-263.

Vincent SR, Hokfelt T, Christensson I, Terenius L (1982) Immunohistochemical evidence for a dynorphin immunoreactive striatonigral pathway. Eur J Pharmacol 85:251-252.

Wilson CJ, Groves PM (1980) Fine structure and synaptic connections of the common spiny neuron of the rat neostriatum. A study employing intracellular injection of horseradish peroxidase. J Comp Neurol 194:599-615. 


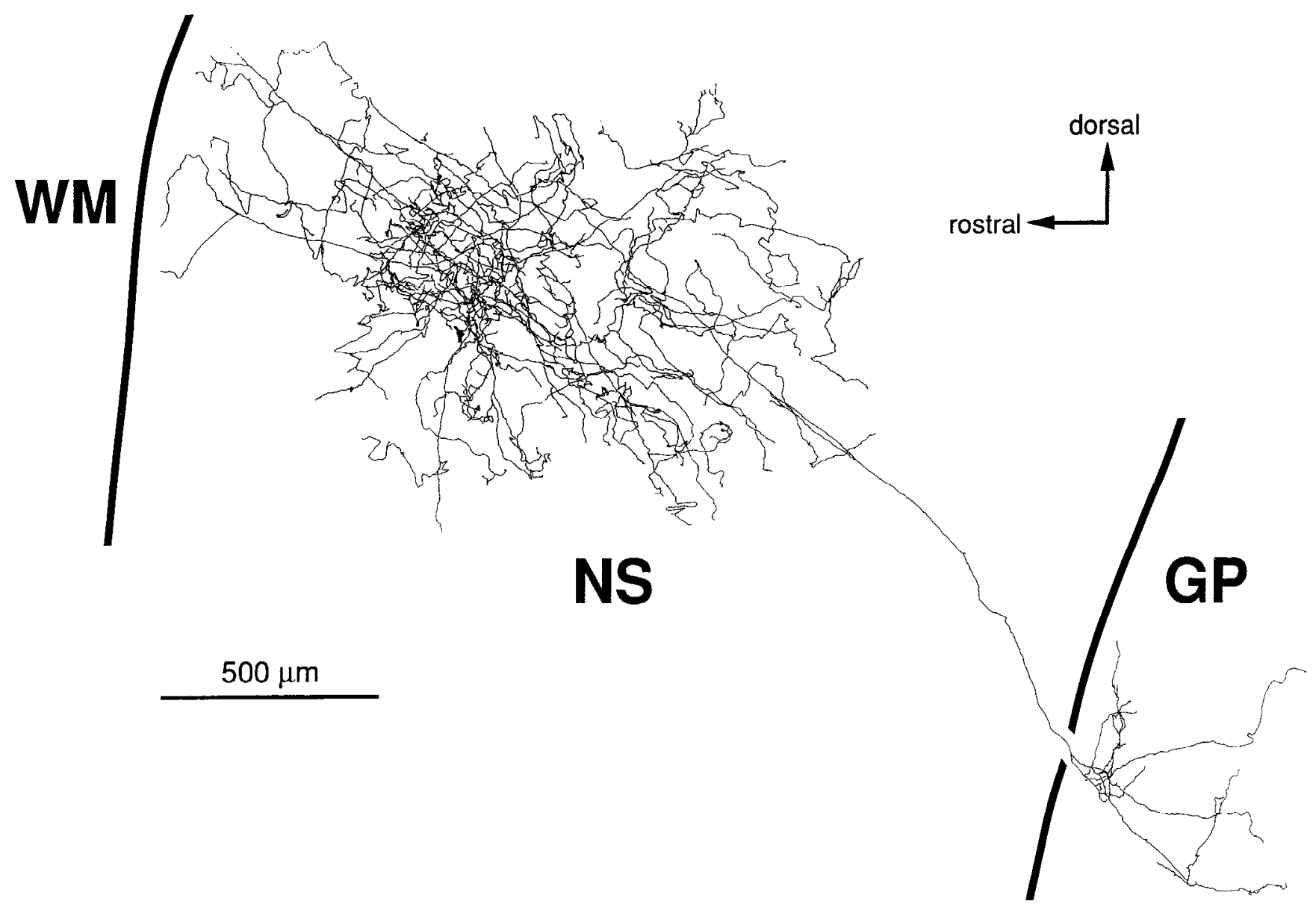

Figure 14. Local axon collaterals and projection to GP of same cell shown in Figure 14. The ramification of intrastriatal axon collaterals of this cell was much wider distributions than type I, type IIa, and type IIb cells described above and extended for $1100 \mu \mathrm{m}$ mediolaterally. The main axon entered the GP and issued collaterals at the border of the NS and the GP. Because the staining became faint in the GP, the efferent projection pattern is unknown. WM, white matter.

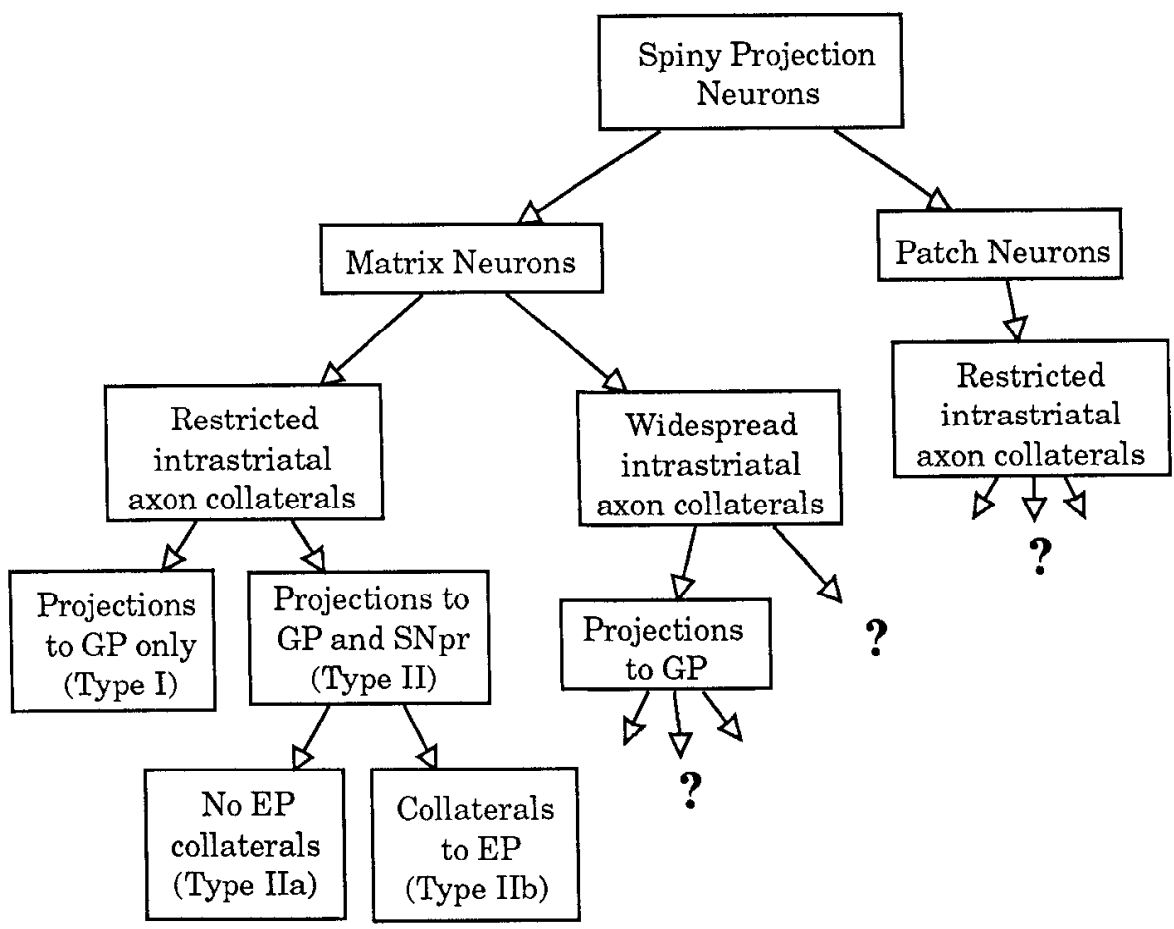

Figure 15. Diagram showing categorization scheme for striatal projection neurons and cell types identified in present study. Only the data from single-neuron staining are shown. While spiny neurons in the patches are known to project to the $\mathrm{SN}$, it is not known what patterns of branching to different targets are expressed by these cells. Likewise, the axonal branching patterns of the relatively rare neurons with widespread intrastriatal axonal arborizations are not known, though at least some of these neurons have axonal arborizations in the GP. The majority of projection neurons are represented by the 3 axonal patterns observed in this study, which are projections to the GP only, branched projections to the GP and $\mathrm{SN}$, and branched projections to the GP, SN, and EP. 
Wilson CJ, Phelan KD (1982) Dual topographic representation of neostriatum in the globus pallidus of rats. Brain Res 243:354-359.

Wilson CJ, Chang HT, Kitai ST (1983a) Origins of postsynaptic potentials evoked in spiny neostriatal projection neurons by thalamic stimulation in the rat. Exp Brain Res 51:217-226.

Wilson CJ, Chang HT, Kitai ST (1983b) Disfacilitation and longlasting inhibition of neostriatal neurons in the rat. Exp Brain Res 51: 227-235.

Wilson CJ, Groves PM, Kitai ST, Linder JC (1983c) Three-dimen- sional structure of dendritic spines in the rat neostriatum. J Neurosci 3:383-398.

Wilson CJ, Chang HT, Kitai ST (1990) Firing patterns and synaptic potentials of identified giant aspiny interneurons in the rat neostriatum. J Neurosci 10:508-519.

Yoshida M, Rabin A, Anderson M (1972) Monosynaptic inhibition of pallidal neurons by axon collaterals of caudate nigral fibcrs. Exp Brain Res 15:337-347. 